UNIVERSIDADE DO VALE DO TAQUARI - UNIVATES

PROGRAMA DE PÓS-GRADUAÇÃO EM AMBIENTE E DESENVOLVIMENTO

Diagnóstico da geração de resíduos sólidos do Sistema Único de Saúde no Vale do Taquari - RS

Juliana Assmann 
Juliana Assmann

\section{Diagnóstico da geração de resíduos sólidos do Sistema Único de Saúde no Vale do Taquari - RS}

Dissertação apresentada ao Programa de Pós-Graduação em Ambiente e Desenvolvimento, da Universidade do Vale do Taquari - UNIVATES, como parte da exigência para obtenção do título de Mestre em Ambiente e Desenvolvimento na área de concentração Tecnologia e Ambiente

Orientador: Prof. Dr. Eduardo Miranda Ethur

Coorientadora: Prof. Dra. Carla Kauffmann 
Juliana Assmann

\title{
DIAGNÓSTICO DA GERAÇÃO DE RESÍDUOS SÓLIDOS DO SISTEMA ÚNICO DE SAÚDE NO VALE DO TAQUARI.
}

\begin{abstract}
A Banca examinadora abaixo aprova a Dissertação apresentada ao Programa de PósGraduação em Ambiente e Desenvolvimento, da Universidade do Vale do Taquari Univates, como parte da exigência para a obtenção do título de Mestre em Ambiente e Desenvolvimento, na área de concentração Tecnologia e Ambiente.
\end{abstract}

Orientador: Prof. Dr. Eduardo Miranda Ethur Universidade do Vale do Taquari - Univates

Coorientadora: Prof. Dra. Carla Kauffmann Universidade do Vale do Taquari - Univates

Dra. Cássia Regina Gotler Medeiros Universidade do Vale do Taquari - Univates

Dra. Simone Stülp

Universidade do Vale do Taquari - Univates

Dra. Simone Cristina Baggio Gnoatto Universidade Federal do Rio Grande do Sul - UFRGS

Lajeado/RS, novembro de 2020. 


\section{RESUMO}

A geração de resíduos sólidos de saúde (RSS), em especial os medicamentos, constitui-se em um dos desafios da sociedade moderna. Medicamentos vencidos ou não utilizados devem ser descartados de forma adequada, para evitar o aumento da carga poluidora no meio ambiente e visando aderir a uma atitude sustentável, porém o que se percebe é que o rejeite realizado inadequadamente é um hábito comum para a população. Dessa forma, objetivo deste trabalho foi realizar um diagnóstico da geração de resíduos de saúde no município de Lajeado - RS, bem como delinear um panorama de como a temática está sendo abordada pelos gestores e responsáveis pela Assistência Farmacêutica (AF) nos outros 36 municípios que compõem o Vale do Taquari (VT) - RS. Trata-se de um estudo transversal realizado no período de 2019 a 2020 no VT - RS. Os profissionais responsáveis pela AF nas secretarias de saúde dos municípios do Vale responderam o questionário composto por questões sobre o Plano de Gerenciamento de Resíduos Sólidos de Saúde (PGRSS). Em Lajeado foi realizada pesquisa através da aplicação de questionário aos munícipes sobre o descarte de medicamentos, além de compilação de dados sobre o descarte de medicamentos na rede pública de saúde. As análises dos questionários dos 36 municípios que formam o VT indicam um índice de respostas de $44,4 \%$, sendo que $50,0 \%$ dos municípios participantes possuem plano de gerenciamento de resíduos (PGRSS). Quanto às orientações, $81,3 \%$ dos municípios relatam realizar campanhas de educação em saúde referente a temática. A pesquisa foi realizada com 277 usuários, moradores da cidade de Lajeado e frequentadores da Farmácia-Escola (FE) e dispensários do município de Lajeado - RS, a maneira de como os mesmos descartam os medicamentos foi abordada. Foi identificado que $98,9 \%$ dos entrevistados possuem medicamentos em suas residências onde em $82,8 \%$ dos casos ocorre vencimento. As análises realizadas em estudos identificaram que 0 assunto precisa ser amplamente divulgado, levando em consideração o impacto ambiental que os resíduos de medicamentos estão causando. Desta forma ressaltase a importância de um plano de gerenciamento bem estruturado tendo em vista a legislação vigente e características locais de cada município, e em contrapartida observou-se o impacto econômico para o município de Lajeado - RS. 
Palavras-chave: Saúde Ambiental. Gerenciamento de Resíduos Sólidos. Medicamentos. Resíduos de Serviço de Saúde. Gestão de Resíduos. Plano de Gerenciamento de Resíduos de Serviço de Saúde. 


\begin{abstract}
The generation of solid health residues (RSS), especially medicines, is one of the challenges of modern society. Expired or unused drugs must be disposed of properly, to avoid increasing the polluting load on the environment and aiming to adhere to a sustainable attitude, but what is perceived is that the rejection carried out improperly is a common habit for the population. Thus, the objective of this work was to carry out a diagnosis of the generation of health waste in the municipality of Lajeado - RS, as well as to outline an overview of how the theme is being addressed by managers and those responsible for Pharmaceutical Assistance (PA) in the other 36 municipalities that make up the Taquari Valley (VT) - RS. This is a cross-sectional study carried out from 2019 to 2020 at VT - RS. The professionals responsible for PA in the health departments of the municipalities of the Vale answered a questionnaire composed of questions about the Health Solid Waste Management Plan (PGRSS). In Lajeado, a survey was carried out through the application of a questionnaire to residents on the disposal of medicines, in addition to the compilation of data on the disposal of medicines in the public health system. The analysis of the questionnaires of the 36 municipalities that make up the VT indicate a response rate of $44,4 \%$, with $50,0 \%$ of the participating municipalities having a waste management plan (PGRSS). As for the guidelines, $81.3 \%$ of the municipalities reported carrying out health education campaigns related to the theme. The survey was conducted with 277 users, residents of the city of Lajeado and frequenters of the Pharmacy School and dispensaries in the municipality of Lajeado - RS, the way they discard the drugs was addressed, identifying that $98.9 \%$ of the interviewees have medicines in their homes where $82.8 \%$ of the cases are due. The analyzes carried out in studies identified that the subject needs to be widely publicized, taking into account the environmental impact that drug residues are causing. Thus, the importance of a well-structured management plan is emphasized, in view of the current legislation and local characteristics of each municipality, and in contrast, the economic impact for the municipality of Lajeado - RS was observed.
\end{abstract}

Keywords: Environmental Health. Solid Waste Management. Health Service Waste. Waste Management. Health Service Waste Management Plan. 


\section{LISTA DE ILUSTRAÇÕES}

\section{LISTA DE FIGURAS}

Figura 1. Localização dos municípios do Vale do Taquari ........................................38

Figura 2. Manejo de Medicamentos Vencidos....................................................47

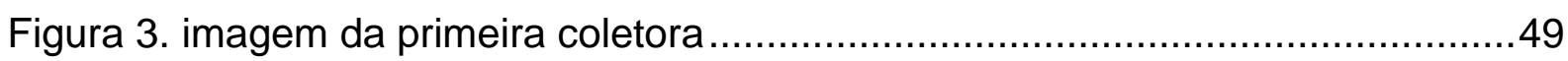

Figura 4. (a) Maquete do dispositivo de segurança utilizados nas coletoras (esquerda); e b) Coletoras encaminhadas as US (direita). .51

\section{LISTA DE QUADROS}

Quadro 1.Percepções dos colaboradores dos dispensários sobre a implantação das coletoras nas US do município de Lajeado - RS. .52

\section{LISTA DE TABELAS}

Tabela 1. Identificação de fármacos em águas no mundo .25

Tabela 2. Características do recolhimento de RSS no âmbito do SUS no Vale do Taquari - RS ( $n=16)$. .40

Tabela 3. Informações coletadas junto a amostra populacional do munícipio de Lajeado - RS sobre o descarte de medicamentos $(n=277)$. 
Tabela 4. Caracterização dos RSS descartados nas coletoras disponíveis nas US do município de Lajeado - RS, no ano de 2019 ( $n=178.564)$. .54

Tabela 5. Caracterização dos medicamentos pertencentes a REMUME descartados nas coletoras disponíveis nas US do município de Lajeado - RS, no ano de 2019 $(n=134.300)$. 55

Tabela 6. Distribuição dos medicamentos descartados quanto ao grupo farmacológico de acordo com segundo nível da ATC $(n=134208)$. .56 


\section{LISTA DE ABREVIATURAS E SIGLAS}

ABNT - Associação Brasileira de Normas Técnicas

ACS - Agente Comunitário de Saúde

ANVISA - Agência de Vigilância Sanitária

APS - Atenção Primária à Saúde

CFF - Conselho Federal de Farmácia

CNEN - Comissão Nacional de Energia Nuclear

CONAMA - Conselho Nacional do Meio Ambiente

CRS - Coordenadoria Regional de Saúde

EMEF - Escola Municipal de Ensino Fundamental

FE - Farmácia-Escola

FEPAM - Fundação Estadual de Proteção Ambiental

LG - Logística Reversa

MEEP - Mostra de Ensino, Extensão e Pesquisa

OMS - Organização Mundial da Saúde

PERS - Plano Estadual de Resíduos Sólidos

PGRSS - Plano de Gerenciamento de Resíduos Sólidos de Saúde

PNRS - Política Nacional de Resíduos Sólidos

PNUMA - Programa das Nações Unidas para o Meio Ambiente

RDC - Resolução de Diretoria Colegiada

RSS - Resíduos Sólidos de Saúde

SINEPE - Sindicato do Ensino Privado

SNIS - Sistema Nacional de Informação Sobre Saneamento 
SUS - Sistema Único de Saúde

TCLE - Termo de Consentimento Livre e Esclarecido

US - Unidade de Saúde

VT - Vale do Taquari 


\section{SUMÁRIO}

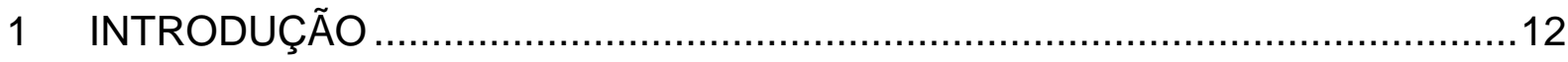

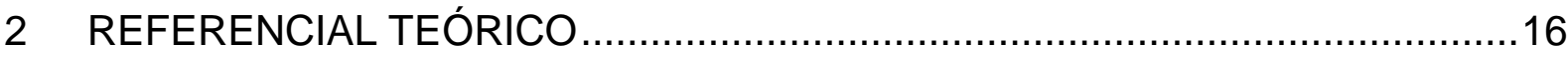

2.1 Resíduos Sólidos de Saúde: contextualização e um panorama mundial .....16

2.2 Gerenciamento de Resíduos Sólidos em Saúde ......................................19

2.3 Políticas Públicas de Descarte de Medicamentos......................................22

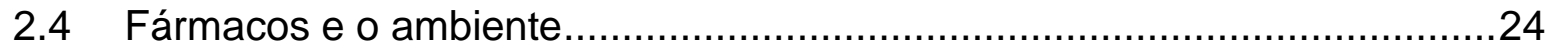

2.5 Razões para Descarte de Medicamentos ……......................................27

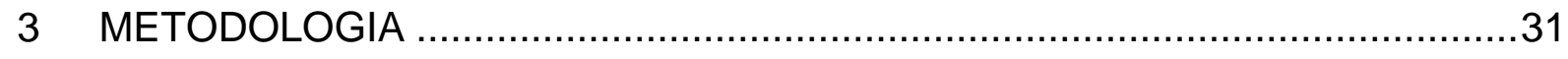

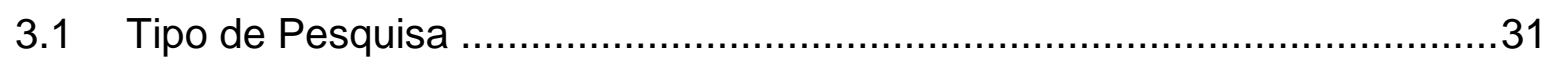

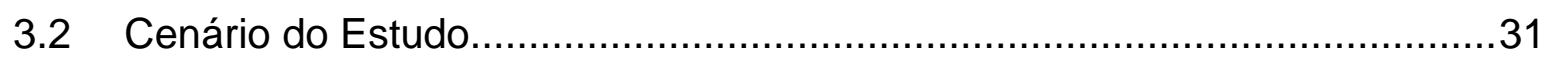

3.2.1 Critérios de Inclusão e Exclusão.......................................................32

3.3 Instrumento de coleta de dados ............................................................

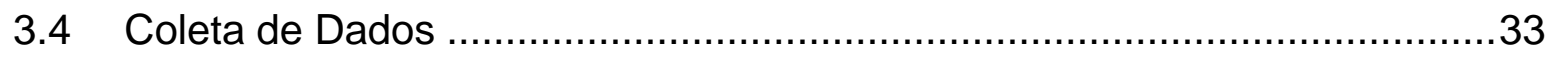

3.4.1 Organização e Tratamento de Dados ..................................................34

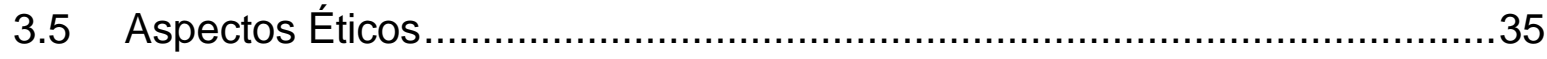

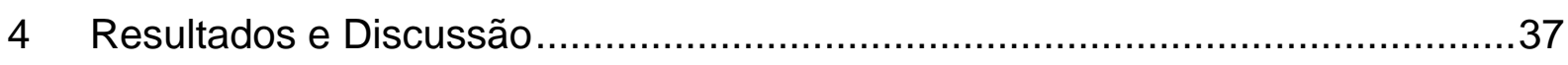

4.1 Contextualização e panorama do descarte de medicamentos e correlatos no

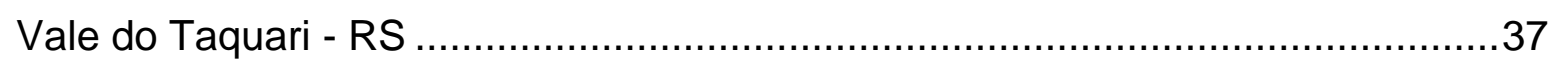

4.2 Panorama do descarte de medicamentos e correlatos no município de

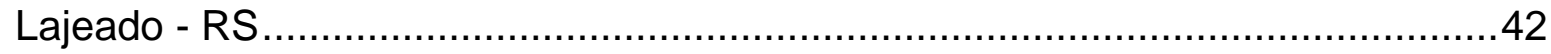

4.2.1 Conhecimento da população do município de Lajeado - RS sobre o descarte de medicamentos e correlatos. 
4.2.2 Promoção do uso racional de medicamentos e de práticas ambientalmente corretas através da educação em saúde: parceria entre Universidade e Poder Público

4.2.3 Caracterização dos resíduos descartados nas coletoras de medicamentos vencidos e/ou em desuso do município de Lajeado - RS .53

5 CONCLUSÃO .60 


\section{INTRODUÇÃO}

O mercado farmacêutico teve um expressivo desenvolvimento no ano de 2018, crescendo $11 \%$ e com faturamento de aproximadamente $\mathrm{R} \$ 90$ bilhões, destacandose a fabricação e desenvolvimento de fármacos, sendo este, o setor farmacêutico que mais investe em pesquisa e desenvolvimento no mundo. Investimentos estes que até o ano de 2024 devem chegar a US\$204 bilhões, justificados pela necessidade de novas terapias, uma vez que a população está ficando mais idosa, além da complexidade e aumento da incidência de doenças crônicas (INTERFARMA, 2019).

Um fator que contribui para a ampliação e manutenção do mercado farmacêutico é a prática da automedicação. A automedicação, conforme a Organização Mundial da Saúde (OMS) ressalta, é adequada quando orientada por profissionais qualificados, tornando-se assim benéfica para os sistemas públicos de saúde, uma vez que diminui a demanda por atendimentos em casos de problemas de saúde menores. No entanto, de forma irracional essa prática contribui para o consumo excessivo e para o descarte, pois os medicamentos muitas vezes não consumidos em sua totalidade, acabam permanecendo armazenados nos domicílios (FERNANDES et al., 2020).

A disponibilidade de medicamentos associada a facilidade de acesso em muitos casos, somada a falta de informação, orientação e pelo assunto não ser amplamente abordado, faz com que grande parte dos resíduos sólidos de saúde (RSS) acabem por serem descartados no lixo doméstico. O descarte inadequado de 
medicamentos, ainda, está relacionado a sobras devido ao prazo de validade expirado, desuso, compra de medicamentos não fracionáveis, entre outras causas (UEDA 2009).

A Resolução da Diretoria Colegiada (RDC) n 80/2006 da Agência Nacional de Vigilância Sanitária (ANVISA) dispõe sobre o fracionamento de medicamentos em farmácias e drogarias. A RDC aponta para uma prática que vai ao encontro do uso racional de medicamentos, indicando que o paciente receba a quantidade adequada, conforme prescrição médica, do medicamento a ser administrada durante o período de tratamento instituído, evitando sobras e consequentemente prazo de validade expirado, uso irracional e descarte incorreto. Contudo, no mercado brasileiro estão disponíveis apenas 549 especialidades farmacêuticas passíveis de fracionamento (ANVISA, 2020).

A conscientização quanto ao descarte correto é um processo lento, porém o assunto já é abordado em normas gerais ou específicas para determinados setores da cadeia de produção farmacêutica, como a RDC n. ํ 222/2018 da ANVISA, Resolução no 358/2005 do Conselho Nacional do Meio Ambiente (CONAMA) e RDC n. ${ }^{-17 / 2010}$ da ANVISA. A maneira correta de descarte de medicamentos vem sendo discutida, mas a sua prática ainda deixa a desejar se tornando uma preocupação constante da sociedade em diversos países (AURÉLIO, 2015).

No Brasil no âmbito da Política Nacional de Resíduos Sólidos (PNRS), foi criada a Lei n. $\stackrel{0}{12.305}$, de 2010 que apesar de não tratar diretamente de medicamentos, ressalta o tema da logística reversa, que deve ser aplicada tanto no âmbito público como no privado (BRASIL, 2010). Quanto aos crimes ambientais, existe a Lei Federal 9605/98 que dispõe sobre as sanções penais e administrativas derivadas de condutas e atividades lesivas ao meio ambiente, e dá outras providências (BRASIL, 1998).

Para elaboração de um PGRSS, o mesmo deve seguir as orientações da RDC n. ${ }^{\circ} 222 / 2018$ da ANVISA e da resolução do CONAMA n. ㅇ 358/2005. Os medicamentos são mencionados como parte de resíduos componentes do grupo $\mathrm{B}$ e 
devem ser submetidos a tratamento e disposição final ambientalmente apropriada. Nesse sentido surge a necessidade de estudar a questão, integrando esforços de todos os profissionais, gestores e poder público em busca de uma solução, para o acondicionamento adequado dos resíduos e agraciar o meio ambiente com a diminuição deste impacto.

O interesse pela temática dos RSS se torna relevante em virtude da crescente problemática dos impactos causados ao meio ambiente, do crescimento populacional, aumento da expectativa de vida e paralelamente o aumento da necessidade de tratamento de doenças, além da falta de informação da população quanto ao assunto. Mesmo gerando interesse pela comunidade científica, pouco se tem feito para a conscientização e sensibilização da população e de gestores para as boas práticas de seu uso e descarte mesmo com legislação existente. Conforme informações do Conselho Federal de Farmácia (CFF), o Brasil ocupa a sexta posição entre os maiores consumidores de medicamentos no cenário mundial. A expectativa é de que, até o final deste ano, o país alcance a quarta posição, ficando atrás somente dos Estados Unidos, China e Japão (CFF, 2017).

Mudanças são necessárias, principalmente no que diz respeito à educação dos profissionais de saúde envolvidos nos processos diretamente ligados ao medicamento, dado o potencial risco à saúde humana e ao meio ambiente que os mesmos carregam. Portanto, pensando na redução de danos, a educação em saúde é um viés de interesse relevante para abordagem da questão apresentada.

Considerando o exposto, o presente trabalho teve por objetivo geral analisar o descarte de medicamentos no Vale do Taquari - RS. Como objetivos específicos foram elencados:

- Verificar o cumprimento da legislação sanitária vigente quanto ao descarte de medicamentos na rede pública de saúde em municípios do Vale do Taquari RS;

- Averiguar como a população do município de Lajeado descarta os resíduos de medicamentos; 
- Analisar o impacto econômico do descarte de medicamentos na rede pública de saúde do município de Lajeado. 


\section{REFERENCIAL TEÓRICO}

\subsection{Resíduos Sólidos de Saúde: contextualização e um panorama mundial}

Apesar de ser um tema discutido atualmente, esta preocupação já está em evidência a longos anos. Os seres humanos sempre geraram resíduos, e desde o momento em que se constituíram por sociedades um expressivo aumento pode ser percebido (DEUS; BATTISTELLE; SILVA, 2015).

Anteriormente à Revolução Industrial, para alguns países, o gerenciamento de resíduos sólidos não era um problema até que, com o significativo aumento populacional e a geração de resíduos como resultado dos processos, se tornou um problema sanitário e que poderia desencadear graves problemas de saúde. A partir daí políticas de saúde pública foram criadas e os resíduos começaram a tornar-se importantes (WILSON, 2007; WORRELL \& VESILIND, 2011).

O crescimento econômico é uma das causas para o uso excessivo de recursos naturais que tem como resultado a geração de resíduos. O princípio dos 5 R's conduz a prática da redução do consumo e preferência por produtos que gerem menos resíduos, reutilização de embalagens e reciclagem, que abrange a transformação de materiais em matérias primas para a produção de outros produtos (BRASIL, 2005; MARCHI, 2011).

O Programa das Nações Unidas para o Meio Ambiente (PNUMA) com sua 
fundação em 1972, tem como compromisso impulsionar a conservação do meio ambiente e a devida utilização de recursos no âmbito do desenvolvimento sustentável. A utilização adequada e a produção e consumo sustentáveis se destacam como as principais áreas temáticas de atuação do programa (PNUMA, 1975).

Diversas são as campanhas de conscientização quanto ao cuidado com o meio ambiente realizados pelo PNUMA e neste ano, o recente concurso finalizado no mês de outubro de 2020, denominado Innovation for Sustainable Lifestyles, realizado nos países da Costa Rica, México e Colômbia, desafiou estudantes de graduação e pósgraduação a desenvolverem iniciativas de atitudes e consumos sustentáveis. Os vencedores foram um grupo de estudantes da Costa Rica, que desenvolveu um blister para embalagens de medicamentos chamado "Ecoblist", produzido com polímeros biodegradáveis à base de mandioca que formam uma lâmina plástica resistente a umidade e calor, alternativa para diminuição de plásticos gerados que representa um problema ambiental e pela ampla utilização de medicamentos pela população (PNUMA, 2020).

Programas de descarte, especificamente para resíduos de saúde, foram criados em países como a Suécia no ano de 2001, que realizou um projeto financiado pelo governo chamado Apoteket $A B$, onde foram coletados 65 a $75 \%$ dos medicamentos não utilizados correspondendo a 1100 toneladas/ano, a estratégia de divulgação alcançou o público em geral e farmácias com a entrega de folders como alternativa de informação ao descarte em local adequado, incentivando a logística reversa (AURÉLIO, 2015).

Em 1993, a França com subsídio das indústrias farmacêuticas para coleta e destinação final dos resíduos, coletou em torno de $77 \%$ da quantidade de medicamentos descartados, equivalente a 14.000 toneladas/ano (AURÉLIO, 2015). Desde 2014 com o objetivo de promover o uso racional de medicamentos e a coleta de medicamentos não utilizados, vencidos ou em desuso, o Groupe VYV (grupo líder em saúde na França) e a Cyclamed (programa de descarte) mantêm uma parceria com objetivos de contribuir para a preservação do meio ambiente e segurança 
sanitária nacional, sendo para promover o uso racional de medicamentos, realização de campanhas de sensibilização e promoção do gesto de eco cidadão dirigido aos diversos envolvidos do sistema, como pacientes, farmácias, profissionais de saúde e meio ambiente. Para o programa a boa gestão de medicamentos não utilizados é um verdadeiro problema de saúde pública, descartados no lixo ou no vaso sanitário, eles têm um impacto prejudicial ao meio ambiente, além de que também podem ser fontes de intoxicação (CYCLAMED, 2020). Meados dos anos 2000 Austrália, Portugal e Espanha perceberam a relevância da temática e aderiram a programas de coletas com auxílio de indústrias, distribuidoras e farmácias (MEDEIROS; MOREIRA; LOPES, 2014; AURÉLIO, 2015).

No Brasil, houve considerável avanço após a Lei 12.305/2010 que regulamenta a Política Nacional de Resíduos Sólidos (PNRS), pois com o sancionamento da legislação discussões foram provocadas sobre a responsabilidade de todos envolvidos na cadeia de processos do produto bem como a logística reversa (AURÉLIO, 2015).

Programas foram criados em todo o país, partindo de iniciativas de redes de farmácia, supermercados e universidades. Os programas Destino Certo e Descarte Consciente tiveram seu início no mesmo ano da publicação da PNRS com suas estratégias de coleta em farmácias. No primeiro ano, 2010 a 2011 o programa Destino Certo, realizado na cidade de Porto Alegre - RS, coletou cerca de 3 toneladas de medicamentos vencidos nas 28 drogarias participantes. Conforme o site do programa, anualmente, é coletado 4 toneladas de medicamentos vencidos e descartados corretamente (BHS, 2020).

$\mathrm{Na}$ região Sudeste, o programa foi denominado Descarte Correto de Medicamentos e teve seu início no ano de 2012, com o apoio de rede de supermercados e farmácia, porém o local de coleta selecionado foram os supermercados, diferentemente dos outros dois programas citados acima. Nos dois primeiros meses de campanha foram descartados $348 \mathrm{~kg}$ de resíduos de medicamentos. Em todos os programas brasileiros de descarte a forma de divulgação 
para a temática foi feita em meios de comunicação como internet, rádio, tv, revistas e jornais, forma esta que abrange diversos tipos de público (AURÉLIO, 2015).

A Política Nacional de Resíduos Sólidos (PNRS) instituída pela lei 12.305/10 aborda um conjunto de diretrizes com o objetivo de reduzir a quantidade de resíduos encaminhados aos aterros e lixões bem como a gestão e gerenciamento destes, mas nada constava em específico para os medicamentos até recentemente, com a publicação do Decreto Federal no 10.388/2020 onde o mesmo estrutura a inserção do sistema de logística reversa de resíduos provindos de medicamentos vencidos e/ou em desuso dos domicílios, enfatizando o descarte para medicamentos de posse do usuário, seja em sua residência ou local de trabalho (BRASIL, 2010).

A RDC n. ํ 222/2018 visa o fortalecimento do decreto e traz a discussão e importância do tema, porém o processo está passando por um período de implantação com adaptações que se estenderão nos dois primeiros anos com adequação de drogarias e distribuidoras parceiras para o destino final aos resíduos (BRASIL, 2018).

Com a publicação da RDC n. 222, a responsabilidade das indústrias farmacêuticas com a legislação é colocada em discussão, visto que hoje em dia a fiscalização não é uma prática ativa, mas a logística reversa é assunto temido pelas indústrias pois responsabiliza os distribuidores em transportar os medicamentos até o produtor inicial para o mesmo realizar o correto destino de descarte (BRASIL, 2018).

O descarte inadequado de medicamentos, sejam sobras ou fora do prazo de validade, ocasiona em contaminação do solo, desenvolvimento de resistência bacteriana entre diversos danos ao meio ambiente além de potencial perigo para saúde (PINTO et al., 2014).

\subsection{Gerenciamento de Resíduos Sólidos em Saúde}

Os Resíduos de Serviços de Saúde - RSS, segundo a Associação Brasileira de 
Normas Técnicas (ABNT), são aqueles gerados em qualquer serviço prestador de assistências médicas, sanitárias ou estabelecimentos congêneres, podendo então ser provenientes de hospitais, farmácias, unidades ambulatoriais de saúde, clínicas e consultórios médicos, laboratórios de análises clínicas e patológicas, instituições de ensino e pesquisa médica, bancos de sangue, clínicas veterinárias e serviços odontológicos (ABNT, 2004).

A ABNT é responsável por diversas normativas no país. A normativa $\mathrm{n} . \stackrel{0}{10.004}$ (2004), descreve sobre substâncias tóxicas, suas características e que apresentem periculosidade aos resíduos sólidos, do qual o impacto à saúde e ao meio ambiente é conhecido. Identificados os constituintes dos medicamentos, os mesmos podem ser enquadrados em classes, neste caso se enquadram como resíduos classe I por suas substâncias químicas e risco de toxicidade, assim sendo considerados resíduos perigosos e que necessitam tratamento adequado (ABDI, 2013).

De acordo com a RDC ANVISA n. $\stackrel{\circ}{222}$ de 28 de março de 2018, regulamenta as Boas Práticas de Gerenciamento de Resíduos Sólidos em Saúde, e desta forma todo estabelecimento deve gerenciar os RSS, desde a geração até o destino final, para essa ação denominou-se de manejo, no qual estão incluídas as seguintes etapas:

SEGREGAÇÃO: Separação dos resíduos, conforme a classificação dos grupos, no momento e local de sua geração, de acordo com as características físicas, químicas, biológicas, o seu estado físico e os riscos envolvidos.

- $\quad$ GRUPO A (Resíduos infectantes): Resíduos com a possível presença de agentes biológicos que, por suas características, podem apresentar risco de infecção; - GRUPO B (Resíduos com risco químico): Resíduos contendo produtos químicos que podem apresentar risco à saúde pública ou ao meio ambiente, dependendo de suas características de inflamabilidade, corrosividade, reatividade e toxicidade; 
- GRUPO C (Rejeitos radioativos): Quaisquer materiais resultantes de atividades humanas que contenham radionuclídeos em quantidades superiores aos limites de isenção especificados nas normas do CNEN e para os quais a reutilização é imprópria.

- GRUPO D (Resíduos comuns): Resíduos que não apresentam risco biológico, químico ou radiológico à saúde ou ao meio ambiente, podendo ser equiparados aos resíduos domiciliares;

- GRUPO E (Materiais perfurocortantes): Resíduos perfurocortantes ou escarificantes, tais como: lâminas de barbear, agulhas, escalpes, ampolas de vidro, brocas, limas endodônticas, fios ortodônticos cortados, próteses bucais metálicas inutilizadas, pontas diamantadas, lâminas de bisturi, lancetas, tubos capilares, micropipetas, lâminas e lamínulas, espátulas e todos os utensílios de vidro quebrados no laboratório (pipetas, tubos de coleta sanguínea e placas de Petri);

ACONDICIONAMENTO: Ato de embalar os resíduos segregados em sacos ou recipientes que evitem vazamentos, e quando couber, sejam resistentes às ações de punctura, ruptura e tombamento, e que sejam adequados física e quimicamente ao conteúdo acondicionado.

IDENTIFICAÇÃO DOS RSS: Conjunto de medidas que permite o reconhecimento dos riscos presentes nos resíduos acondicionados, de forma clara e legível em tamanho proporcional aos sacos, coletores e seus ambientes de armazenamento.

ARMAZENAMENTO INTERNO: Guarda dos resíduos contendo produto químico ou radioativo na área de trabalho.

ARMAZENAMENTO TEMPORÁRIO: Guarda temporária dos coletores de resíduos de serviços de saúde, em ambiente próximo aos pontos de geração, visando agilizar a coleta no interior das instalações e otimizar o deslocamento entre os pontos geradores e o ponto destinado à apresentação para coleta externa;

ARMAZENAMENTO EXTERNO: Guarda dos coletores de resíduos em ambiente 
exclusivo, com acesso facilitado para a coleta externa;

COLETA E TRANSPORTE INTERNO: Traslado dos resíduos dos pontos de geração até o abrigo temporário ou o abrigo externo.

COLETA E TRANSPORTE EXTERNOS: Remoção dos RSS do abrigo externo até a unidade de tratamento ou outra destinação, ou disposição final ambientalmente adequada, utilizando-se de técnicas que garantam a preservação das condições de acondicionamento.

TRATAMENTO E DISPOSIÇÃO FINAL: São as etapas finais do gerenciamento de resíduos e ocorrem fora do local de geração. Aplicam-se métodos e processos para eliminar riscos de contaminação, de acordo com as características de cada resíduo, e quando possível, seu reaproveitamento (reciclagem, processamento ou manufatura reversa), do contrário, o envio a aterro licenciado.

No ano de 2018 o Brasil foi o $7^{\circ}$ país no ranking mundial de mercados farmacêuticos e estimativas apontam que até o ano de 2023 deve subir duas posições (INTERFARMA, 2019; AITKEN, 2019). O Programa Descarte Consciente traz dados reais do descarte de medicamentos das empresas conveniadas com o programa e os valores são significantes, cerca de $442.000 \mathrm{~kg}$ foram coletadas até a metade do mês de outubro/2020, assim aproximadamente 200 bilhões de litros de água estão sendo preservados (BHS, 2020).

\subsection{Políticas Públicas de Descarte de Medicamentos}

No Rio Grande do Sul a Lei Estadual n 10.099/1994, dispõe sobre os resíduos sólidos provenientes de serviços de saúde, mas se mostra desatualizada conforme as legislações atuais da Agência Nacional de Vigilância Sanitária ANVISA (RDC n. ำ 222/2018) e do CONAMA (Resolução CONAMA n. $\left.{ }^{\circ} 358 / 2005\right)$. 
Ao encontro da temática do presente estudo a Lei Estadual n. ${ }^{\circ} 13.905 / 2012$, dispõe sobre a obrigatoriedade das farmácias e drogarias manterem recipientes para coleta de medicamentos, cosméticos, insumos farmacêuticos e correlatos em desuso ou com data de validade vencida (RIO GRANDE DO SUL, 2012)

Dois tipos de tratamento de RSS são licenciados no estado do Rio Grande do Sul, sendo eles a autoclavação e incineração. O processo de autoclavação, aplicado em laboratórios para redução de carga microbiana de culturas e estoques de microrganismos, está dispensado de licenciamento ambiental, ficando sob a responsabilidade dos serviços que o possuem, a garantia da eficácia dos equipamentos mediante controles químicos e biológicos periódicos devidamente registrados (ANVISA, 2004).

Dados disponibilizados pela Fundação Estadual de Proteção Ambiental (FEPAM) do Rio Grande do Sul, mostram que a capacidade de tratamento de RSS do Estado é de 55,8 t/dia. No estado do Rio Grande do Sul os geradores de $31 \%$ dos municípios encaminham os RSS para tratamento de autoclavagem, $18 \%$ enviam para incineração e $15 \%$ destinam os RSS para os dois tratamentos citados, conforme informações da FEPAM (2014) e Sistema Nacional de Informação sobre Saneamento (SNIS - 2012)

Os resíduos do grupo $\mathrm{B}$, são os que apresentam risco químico, não possuem tratamento adequado no Rio Grande do Sul e por este motivo necessitam ser encaminhados para tratamento fora do Estado. O destino dado é disposição final em aterros de resíduos industriais classe I quando sólidos pois, segundo Resolução CONAMA 358/2005, quando em estado líquido esses resíduos não podem ser encaminhados para disposição final em aterros pelo contato e contaminação que pode ocorrer com o solo. (PERS-RS, 2014)

O projeto de Lei no 5705/13 relata sobre a participação de farmácias, drogarias e laboratórios farmacêuticos no descarte e na destinação final de medicamentos vencidos ou impróprios para o consumo, em todo Território Nacional. A destinação 
final, ambientalmente adequada ao descarte de medicamentos vencidos ou impróprios para uso, envolve todas unidades de saúde, farmácias, drogarias que ficam obrigadas a instalar pontos de coleta, em local visível, para descarte de medicamentos impróprios para o consumo ou com data de validade vencida (BRASIL, 2013).

O manejo dos RSS é entendido como o conjunto de ações de gestão de resíduos que compreende desde a geração até a disposição final, incluindo as etapas de segregação, acondicionamento, identificação, transporte interno, armazenamento, coleta e transporte externos, tratamento, e disposição final. Os estabelecimentos de serviços de saúde são os responsáveis pelo correto gerenciamento de todos RSS por eles gerados, cabendo aos órgãos públicos, dentro de suas competências, a gestão, regulamentação e fiscalização (ANVISA, 2006).

Conforme o Relatório do Plano Estadual de Resíduos Sólidos do Rio Grande do Sul (PERS - RS) 2012 - 2015, a projeção da geração de RSS até o ano de 2034 vai ultrapassar 68.000 t/ano. Uma explicação para o fato é o aumento da expectativa de vida e com isso o impacto na utilização de quantidades elevadas de medicamentos, desta maneira as políticas vêm ao encontro para uma fiscalização efetiva e para conscientizar a população sobre os impactos ambientais que já são realidade, causados pelo descarte inadequado (PERS-RS, 2014).

\subsection{Fármacos e o ambiente}

Os fármacos são compostos químicos com diversas funcionalidades e propriedades físico-químicas e biológicas. Como contaminantes para o meio ambiente são classificados com a denominação emergente, pois aparentemente não apresentariam potencial risco de toxicidade, visto que não estão descritos nos regulamentos e critérios de qualidade da água. Por este motivo, os compostos químicos não recebem nenhum tipo de tratamento especial quando chegam à rede de tratamento de esgoto (KUMMERER, 2009b; UFRGS, 2018). 
De fato, as concentrações desses compostos químicos são baixas e o risco de toxicidade nos humanos é pequeno, porém não existem estudos que comprovem e identifiquem que a ingestão de água com pequenas concentrações de compostos químicos a longo prazo não seja prejudicial aos humanos (UFRGS, 2018).

Estudos já informam que as classes farmacêuticas como analgésicos, antiinflamatórios e betabloqueadores são os componentes que apresentam maior resistência ao tratamento (taxa de remoção entre 30 e 40\%). Para os antibióticos, a taxa de remoção é de $50 \%$, além de que dependendo das características do solo podem permanecer por muito tempo no ambiente e contaminar a água subterrânea, uma vez que a resistência bacteriana é um problema de saúde pública preocupante (DEBLONDE et al., 2011; TAMTAM et al., 2011).

Nos ambientes aquáticos em todo o mundo, conforme tabela 1, já é possível perceber altas taxas de compostos químicos, como no estudo realizado analisando as águas das praias do Guarujá, na cidade de São Paulo - SP, onde foram identificados fármacos com potenciais impactos ao ambiente, alguns com concentrações acima das permitidas. O que chama atenção é que os medicamentos encontrados nas análises são de uso contínuo, como anti-hipertensivos, anticonvulsivantes, antidepressivos além de anti-inflamatórios e analgésicos (ROVERI et al., 2020).

Tabela 1. Identificação de fármacos em águas no mundo

\begin{tabular}{|c|c|l|}
\hline Matriz ambiental & \multicolumn{2}{c|}{ Localidades } \\
\hline \multirow{7}{*}{$\begin{array}{c}\text { ÁGUAS } \\
\text { SUPERFICIAIS }\end{array}$} & Austrália & Queensland (WATKINSON et al., 2009) \\
\cline { 2 - 3 } & Brasil & $\begin{array}{l}\text { Amazonas (THOMAS et al., 2014); Rio de Janeiro (STUMPF et al., 1999); } \\
\text { São Paulo (ALMEIDA e WEBER, 2005) }\end{array}$ \\
\cline { 2 - 3 } & China & Região Sul (PENG et al., 2014); Taiwan (LIN e TSAl, 2009) \\
\cline { 2 - 3 } & Coréia do Sul & Seul (YOON et al., 2010) \\
\cline { 2 - 3 } & Espanha & $\begin{array}{l}\text { Catalonia (GONZÁLEZ et al., 2012); Região Noroeste (GROS et al., 2010); } \\
\text { Valença (VAZQUEZ-ROIG et al., 2012) }\end{array}$ \\
\cline { 2 - 3 } & França & $\begin{array}{l}\text { BENOTTI et al., 2009; Chicago (BARBER et al., 2011); Minnesota (WRITER } \\
\text { et al., 2013); Região Sudeste (PADHYE et al., 2014) }\end{array}$ \\
\cline { 2 - 3 } & Região Sudoeste (IDDER et al., 2013) \\
\cline { 2 - 3 } & Itália & $\begin{array}{l}\text { Po Valley (AUKIDY et al., 2012); Região Norte e Centro (MEFFE e } \\
\text { BUSTAMANTE, 2014) }\end{array}$ \\
\cline { 2 - 3 } & Japão & Oyamasaki-Yawata (AZUMA et al., 2013) \\
\hline
\end{tabular}




\begin{tabular}{|c|c|c|}
\hline & Países Baixos & Dutch (JONGH et al., 2012) \\
\hline & Reino Unido & $\begin{array}{l}\text { North Yorkshire (ZHOU et al., 2009); País de Gales (KASPRZYK- } \\
\text { HORDERN et al., 2009); BAKER e KASPRZYK-HORDERN, } 2013\end{array}$ \\
\hline & Sérvia & PETRÓVIC et al., 2014 \\
\hline \multirow{6}{*}{$\begin{array}{l}\text { ÁGUAS } \\
\text { SUBTERRÂNEAS }\end{array}$} & Alemanha & Região Meridional (EINSIEDL et al., 2010) \\
\hline & Espanha & $\begin{array}{l}\text { Barcelona (LÓPEZ-SERNA et al., 2013); llha de Mallorca (RODRIGUEZ- } \\
\text { NAVAS et al., 2013) }\end{array}$ \\
\hline & EUA & $\begin{array}{l}\text { Califórnia (FRAM e BELITZ, 2011); Massachusetts (SCHAIDER et al., } \\
\text { 2014); Nebraska (BARTELT-HUNT et al., 2011) }\end{array}$ \\
\hline & Itália & Região Norte e Centro (MEFFE e BUSTAMANTE, 2014) \\
\hline & México & Cidade do México (SIEMENS et al., 2008) \\
\hline & Suíça & Jura (MORASH, 2013) \\
\hline \multirow{3}{*}{ ESTUÁRIOS } & China & Sul da China (XU et al., 2013) \\
\hline & França & Golfo de Lyon (MUNARON et al., 2012) \\
\hline & Portugal & Cidade do Porto (MADUREIRA et al., 2010) \\
\hline \multirow{2}{*}{ MARES } & Espanha & Ilha de Mallorca (RODRIGUEZ-NAVAS et al., 2013) \\
\hline & França & Golfo de Lyon (MUNARON et al., 2012) \\
\hline PEIXES & Argentina & Córdoba (VALDÉS et al., 2014) \\
\hline \multirow{2}{*}{ SEDIMENTOS } & Brasil & Bahia (BERETTA et al., 2014) \\
\hline & Japão & Tokushima (YAMAMOTO et al., 2009) \\
\hline \multirow{4}{*}{ SOLOS } & Espanha & Valença (VAZQUEZ-ROIG et al., 2012) \\
\hline & França & Paris (TAMTAM et al., 2011) \\
\hline & Japão & Tokushima (YAMAMOTO et al., 2009) \\
\hline & México & Cidade do México (SIEMENS et al., 2008) \\
\hline
\end{tabular}

Fonte: Aurélio, 2015

As redes de esgotos podem conter milhares de produtos químicos diferentes que tem potencial para comprometer a qualidade das águas (AURÉLIO, 2015). Dentre esses compostos, na última década, foi percebido um crescente interesse pela indústria farmacêutica e produtos de higiene pessoal, que constituem um grupo de grande número de compostos químicos de diferentes classes terapêuticas, incluindo produtos farmacêuticos como antiepilépticos, estimulantes, analgésicos, antiinflamatórios e anti-hipertensivos (CELLE-JEANTON et al. 2014; LOLIC et al. 2015; PEÑA-GUZMÁN et al. 2019).

O estudo de Roveri et al. (2020) realizou uma avaliação de acordo com o risco ecológico. Para os pontos de amostragem de água localizados diretamente no início dos canais de drenagem urbana, os mais frequentemente fármacos detectados foram carbamazepina, cafeína, cocaína, benzoilecgonina, diclofenaco, valsartana, acetaminofeno, atenolol, losartana, rosuvastatina, clopidogrel, citalopram, 
orfenadrina, propranolol, enalapril e clortalidona. Fármacos como cafeína, acetaminofeno, diclofenaco, valsartana e losartana podem exercer efeitos potencialmente tóxicos para os organismos aquáticos, como peixes, algas e crustáceos (ROVERI et al., 2020).

A diminuição e até mesmo desaparecimento de algumas espécies, consideradas essenciais para seu habitat, pode ser um provável resultado da presença de resíduos de saúde. O aumento de alguns tipos de insetos pode ser justificado pelo desaparecimento de seus predadores naturais. $O$ descarte incorreto de resíduos de saúde juntamente com o alto custo e ausência de um tratamento eficiente para o tratamento correto da água nos faz aumentar a preocupação e a divulgação dessa problemática (UFRGS, 2018).

\subsection{Razões para Descarte de Medicamentos}

O papel que os medicamentos apresentam para a sociedade são de relevante importância, visto que sua função é curativa, profilática, paliativa e para diagnóstico de certas enfermidades. O Brasil está entre os maiores consumidores de medicamentos, diante desta informação a ocorrência de medicamentos vencidos ou em desuso encontrados nas residências se torna significante quando pensarmos em uso racional e descarte adequado (INTERFARMA, 2019).

Os gastos com medicamentos no mundo excederão US $\$ 1,5$ trilhão de dólares no ano de 2023, com uma taxa composta de crescimento anual de 3 a $6 \%$ nos próximos cinco anos. Os principais impulsionadores do crescimento serão os Estados Unidos e os mercados farmacêuticos, com crescimento anual composto de 4 a 7\% e 5 a $8 \%$, respectivamente. Nos Estados Unidos, o crescimento geral dos gastos é impulsionado por uma série de fatores, incluindo a aceitação de novos produtos e preços de marcas, enquanto é compensado por vencimentos de patentes e genéricos (INTERFARMA, 2019). 
Aspectos relacionados ao descarte de medicamentos apresentam-se preocupantes quando estimativas mostram que cerca de 27,5\% dos municípios brasileiros encaminham os resíduos sem o adequado tratamento prévio, o que apresenta riscos aos trabalhadores e meio ambiente (ABRELPE, 2017).

Uma parcela de responsabilidade também pode ser atribuída à população que por desconhecimento sobre o assunto, descartam os medicamentos que sobram ou vencem no lixo doméstico e poucas ações governamentais de educação em saúde. Os medicamentos na sua forma íntegra, descartados de forma incorreta podem ser utilizados de maneira indevida e ainda contaminar o meio ambiente através da água, do solo, causando impactos relevantes a natureza e consequentemente a saúde pública (FALQUETO; KLIGERMAN; ASSUMPÇÃO, 2010)

Para Silva et al (2014), apesar de existirem iniciativas e regulamentações diversas sobre devolução, recolhimento, doação e descarte de medicamentos em desuso, muitas vezes o destino desses produtos acaba sendo o esgoto ou o lixo comum. Esses resíduos quando em contato com o solo e água, podem causar contaminação severa, dificultando a remoção através das estações de tratamento de água e esgoto convencionais, que muitas vezes não possuem tecnologia adequada para remoção de micro poluentes (PINTO et al., 2014).

A participação da população é imprescindível para o correto funcionamento da cadeia de logística reversa. $O$ incentivo e a divulgação da forma correta de descarte dos medicamentos podem ser feitos no momento do uso, disponibilizando as regras sobre o descarte adequado na própria embalagem (BELLAN et al., 2012). Nesse sentido, sem o acordo prévio e o conhecimento da realidade local, regional ou nacional, o planejamento de metas e ações poderá ser inadequado e, assim, os benefícios da gestão de resíduos sólidos não serão eficientes, e os prejuízos ambientais e socioeconômicos continuarão a representar um ônus à sociedade e ao ambiente (IPEA, 2012).

A venda de medicamentos fracionados é uma forma de auxiliar na diminuição 
da produção e no uso racional, minimizando a possibilidade do consumo desnecessário e os possíveis danos ambientais gerados através do descarte inadequado. Evitar que o usuário tenha sobras de medicamentos em casa e impedir o contato direto desses produtos químicos com o meio natural ainda são as melhores formas para reduzir a contaminação (BELLAN et al., 2012). No Brasil, o fracionamento de medicamentos está regulamentado desde 2006 através da RDC nํ80/2006, mas ainda não ocorre na prática (BRASIL, 2006).

Dentre as classes de substância farmacológicas que preocupam pela contaminação, destaca-se os antibióticos, substâncias utilizadas irracionalmente em diversas situações capazes de desenvolver resistência bacteriana no meio ambiente (BILA; DEZOTTI, 2005).

A RDC 20/2011 que trata sobre os antibióticos, define a dispensação da quantidade exata para o período do tratamento medicamentoso prescrito. Se a legislação fosse seguida, provavelmente diminuiria as sobras dessa classe de medicamentos nas residências e consequentemente o descarte incorreto (BRASIL, 2011). Porém esta prática se torna praticamente inviável, pois são poucos os laboratórios farmacêuticos que aderiram a apresentação comercial fracionável, conforme estabelece a RDC 80/2006 (BRASIL, 2006).

Estudos como os realizados por Zaparroli et al. 2011, já comprovam a existência da contaminação ambiental por algumas classes de fármacos. Pizzolato et al 2007, desenvolveu uma metodologia analítica com a finalidade de realizar a quantificação de fármacos usando a cromatografia líquida visando identificar os fármacos em quantidade poluente no meio aquoso (ZAPARROLI et al., 2011; PIZZOLATO, SANTOS, CUNHA; 2007).

Em contrapartida, estudos como Crestana et al. (2011) e Melo et al. (2009) relatam a dificuldade em desenvolver métodos que sejam sensíveis o suficiente para a detecção de fármacos residuais. Ainda Melo et al. (2009) reforça em estudo realizado que os processos convencionais de tratamento de água e esgoto não se 
mostram satisfatórios para a remoção dos resíduos de fármacos, tornando o ambiente aquático mais suscetível à contaminação (MELO et al. 2009)

Justificado pela falta de tecnologias que possibilitem a retirada dos fármacos em sua totalidade torna-se de extrema importância viabilizar ações que promovam o uso racional de medicamentos juntamente com fiscalização efetiva e adequada (CRESTANA et al., 2011; MELO et al.,2009). 


\section{METODOLOGIA}

O trabalho de pesquisa foi realizado no período de janeiro de 2019 a outubro de 2020, assim parte da coleta de dados prevista para o ano corrente foi prejudicada em função da pandemia do novo Sars-Cov-19, precisando realizar-se modificações na metodologia, as quais são descritas a seguir.

\subsection{Tipo de Pesquisa}

A pesquisa realizada configura-se como um estudo transversal, o qual foi realizado no período de janeiro de 2019 a outubro de 2020.

\subsection{Cenário do Estudo}

O estudo foi realizado no Vale do Taquari - RS, tendo como população alvo profissionais da saúde responsáveis pela gerência da AF nas secretarias de saúde dos municípios, além de moradores do município de Lajeado - RS. Esse município também foi alvo de levantamento qualitativo e quantitativo sobre o descarte de medicamentos nas unidades de saúde (US), envolvendo tanto a análise de resíduos descartados, quanto a percepção dos profissionais responsáveis pelos dispensários, locais onde há distribuição de medicamentos, quanto a presença da coletora de medicamentos vencidos e/ou em desuso. 


\subsubsection{Critérios de Inclusão e Exclusão}

O estudo abrangeu municípios pertencentes ao VT - RS, sendo entrevistados profissionais responsáveis pela gerência da AF na secretaria municipal de saúde independentemente de ser farmacêutico ou não. Ainda, foram incluídos municípios independentemente de possuírem ou não uma coletora de medicamentos vencidos e/ou em desuso.

No município de Lajeado, foram incluídos sujeitos com idade igual ou superior a 18 anos, com acesso à internet, e que concordaram com o Termo de Consentimento Livre e Esclarecido (TCLE) na categoria de usuários. No levantamento qualitativo e quantitativo foram incluídas todas as US que realizam entrega de medicamentos e que possuem coletora para coleta desses produtos vencidos ou em desuso. $\mathrm{Na}$ categoria profissionais das US foram incluídos os indivíduos responsáveis pelo dispensário.

Foram excluídos do estudo, na categoria municípios do VT, aqueles que após 6 tentativas de contato com o profissional através de correspondência, e-mail, ligação telefônica e mensagem de texto no período de maio/2019 a setembro/2020, não responderam à entrevista. $\mathrm{Na}$ categoria usuários foram excluídos indivíduos não residentes em Lajeado, com idade inferior a 18 anos e questionários não totalmente respondidos. Quanto aos profissionais das US foram excluídas aqueles que após 2 tentativas de contato presencial com o responsável não estavam disponíveis para responder à entrevista.

\subsection{Instrumento de coleta de dados}

Na coleta de dados direcionada aos gestores da AF nas secretarias municipais de saúde do VT foi empregado um questionário estruturado, elaborado pelos pesquisadores, com questões abertas e fechadas abrangendo o descarte de medicamentos e cumprimento da legislação sanitária vigente quanto ao descarte de 
medicamentos no município.

$\mathrm{Na}$ coleta de dados junto aos munícipes de Lajeado foi utilizado um questionário estruturado, elaborado pelos pesquisadores, com questões abertas, fechadas e de múltipla escolha abordando o descarte de medicamentos. Da mesma forma, a coleta de dados junto aos responsáveis pelos dispensários nas US foi empregado questionário estruturado abordando suas percepções sobre a coletora de medicamentos vencidos e/ou em desuso e seu impacto.

\subsection{Coleta de Dados}

Os profissionais responsáveis pela gestão da AF nos municípios do VT - RS foram convidados a participarem da pesquisa por e-mail, ligação telefônica e mensagem de texto. Primeiramente, o questionário acompanhado pelo TCLE foi encaminhado via correspondência pela 16ª Coordenadoria Regional de Saúde (CRS), porém houve baixa adesão dos profissionais. Dessa forma, o questionário foi sistematizado e novamente encaminhado, precedido do TCLE, desta vez por email, empregando a ferramenta do Google Formulários ${ }^{\circledR}$.

A coleta de dados com os usuários no município de Lajeado - RS seria realizada, primeiramente, com a aplicação do questionário presencialmente, porém, no período da pesquisa ocorreu a pandemia do novo Sars-Cov-19 e, desta forma, a maneira de abordagem precisou ser modificada. A abordagem dos usuários ocorreu de forma online, sendo divulgada por mídias sociais. O questionário para a população foi disponibilizado de forma online, empregando a ferramenta Google Formulários ${ }^{\circledR} \mathrm{e}$ os resultados avaliados em número que atingiu saturação da mostra.

Tanto na categoria profissionais quanto usuários, ao acessar o link para o questionário, primeiramente os participantes foram informados sobre o objetivo da pesquisa e a forma de coleta de dados, bem como ressaltado que os mesmos não seriam expostos a riscos, apenas disponibilização de tempo para preenchimento do 
questionário, e sobre a garantia de sigilo/anonimato quando da divulgação de dados, sendo questionado o aceite do TCLE. A partir do aceite do termo, os indivíduos eram direcionados ao questionário.

Os responsáveis pelos dispensários nas US de Lajeado foram abordados presencialmente e o questionário aplicado na forma de entrevista, no local de trabalho desses indivíduos, após aceite do TCLE.

Os resíduos de medicamentos vencidos e/ou em desuso gerados nas US do município de Lajeado são encaminhados regularmente para o almoxarifado central de medicamentos da secretaria municipal de saúde. No período da pesquisa, entre janeiro e dezembro de 2019, antes do encaminhamento para recolhimento por empresa especializada, os mesmos foram quantificados e qualificados.

\subsubsection{Organização e Tratamento de Dados}

As respostas dos questionários aplicados aos profissionais do VT foram analisadas de forma quantitativa e qualitativa (agrupando as respostas em categorias por similaridade). Os dados coletados junto aos usuários foram analisados de forma quantitativa. Enquanto, os dados coletados junto aos responsáveis pelos dispensários das US de Lajeado foram analisados de forma qualitativa (agrupando as respostas em categorias por similaridade).

Os dados do levantamento qualitativo-quantitativo realizado a partir da separação dos RSS das US do município de Lajeado, abrangendo o ano de 2019 (janeiro a dezembro), foram tabulados em planilhas no programa Microsoft Office Excel 2010. O programa também foi utilizado para análise dos dados compilados.

A análise quantitativa englobou contagem ou pesagem dos RSS, dependendo de suas características. Medicamentos comercializados em dose unitária, como comprimidos, cápsulas e drágeas, foram contabilizados individualmente (por exemplo, um comprimido equivale a uma unidade), enquanto formas líquidas ou semissólidas 
que são disponibilizadas em embalagens de doses múltiplas, foram contados por embalagem (por exemplo, um frasco de xarope equivale a uma unidade). As embalagens primárias de medicamentos (blísteres) vazias foram pesadas.

$\mathrm{Na}$ análise qualitativa dos resíduos de medicamentos vencidos e/ou em desuso foram coletadas as seguintes informações: nome de acordo com a Denominação Comum Brasileira (DCB), concentração e validade e US de origem (dado não apresentado no presente trabalho). $\mathrm{Na}$ análise da validade, os produtos com validade igual ou superior a janeiro de 2020 foram considerados válidos. A partir da DCB e concentração foi possível identificar medicamentos que constam na Relação Municipal de Medicamentos Essenciais (REMUME) do município de Lajeado - RS. A quantificação do valor monetário dos medicamentos descartados foi realizada considerando-se o valor de aquisição dos mesmos no ano de 2020, sendo esse dado disponibilizado pelo município. Ainda, os medicamentos descartados foram categorizados de acordo com a classificação Anatomical Therapeutic Chemical (ATC) (WHO, 2020), adotada pela OMS, sendo que para a análise foi considerado o segundo nível da classificação ATC.

\subsection{Aspectos Éticos}

O projeto foi encaminhado para avaliação do Comitê de Ética em Pesquisa da Univates, seguindo todas as diretrizes da Resolução n. 466 , de 12 de dezembro de 2012, do Conselho Nacional de Saúde aprovado pelo número de parecer 3.438.923.

Os entrevistados foram informados a respeito do projeto, de seus objetivos e metodologia, e convidados a participarem do mesmo. Ainda, foram informados que sua participação não incorria em risco, apenas possível desconforto ao responder o questionário pelo tempo a ser disposto, em torno de 20 minutos. Os dados obtidos durante a pesquisa serão mantidos pelo pesquisador durante 5 anos. Após este período os dados e documentos coletados serão descartados. Ainda, será garantido o sigilo sobre identidade do entrevistado, bem como a possibilidade de interromper a 
participação em qualquer momento da pesquisa e que a participação não incorre em custos ou cachê nem indenizações por parte da equipe de pesquisadores. No caso de anuência de participação na pesquisa, foi solicitado a estes que confirmassem concordando com o Termo de Consentimento Livre e Esclarecido, ficando disponível no link enviado juntamente com o questionário, de acordo com a Resolução 466/2012 do Conselho Nacional de Saúde.

O estudo foi autorizado pela Secretaria de Saúde do município de Lajeado - RS para realização da pesquisa. A carta de anuência solicitada ao responsável, conforme inclusão do mesmo no estudo foi adicionada à Plataforma Brasil. 


\section{Resultados e Discussão}

\subsection{Contextualização e panorama do descarte de medicamentos e correlatos no Vale do Taquari - RS}

O Vale do Taquari, situado na região central do Rio Grande do Sul (RS), é constituído por 37 municípios vinculados à 16 a CRS ocupando uma área de 4.821,1 $\mathrm{km}^{2}$ de área (1,71\% do RS) e possui 351.999 habitantes $(3,11 \%$ da população do $R S)$. O VT possui localização estratégica na Região Central do Estado do Rio Grande do Sul (Figura 1), estando a uma média de 150 quilômetros da capital Porto Alegre, com fácil acesso a outras regiões do Estado, País e exterior por rodovias pavimentadas e um entroncamento intermodal hidroviário, ferroviário e rodoviário (IBGE, 2018). 
Figura 1. Localização dos municípios do Vale do Taquari RIO GRANDE DO SUL

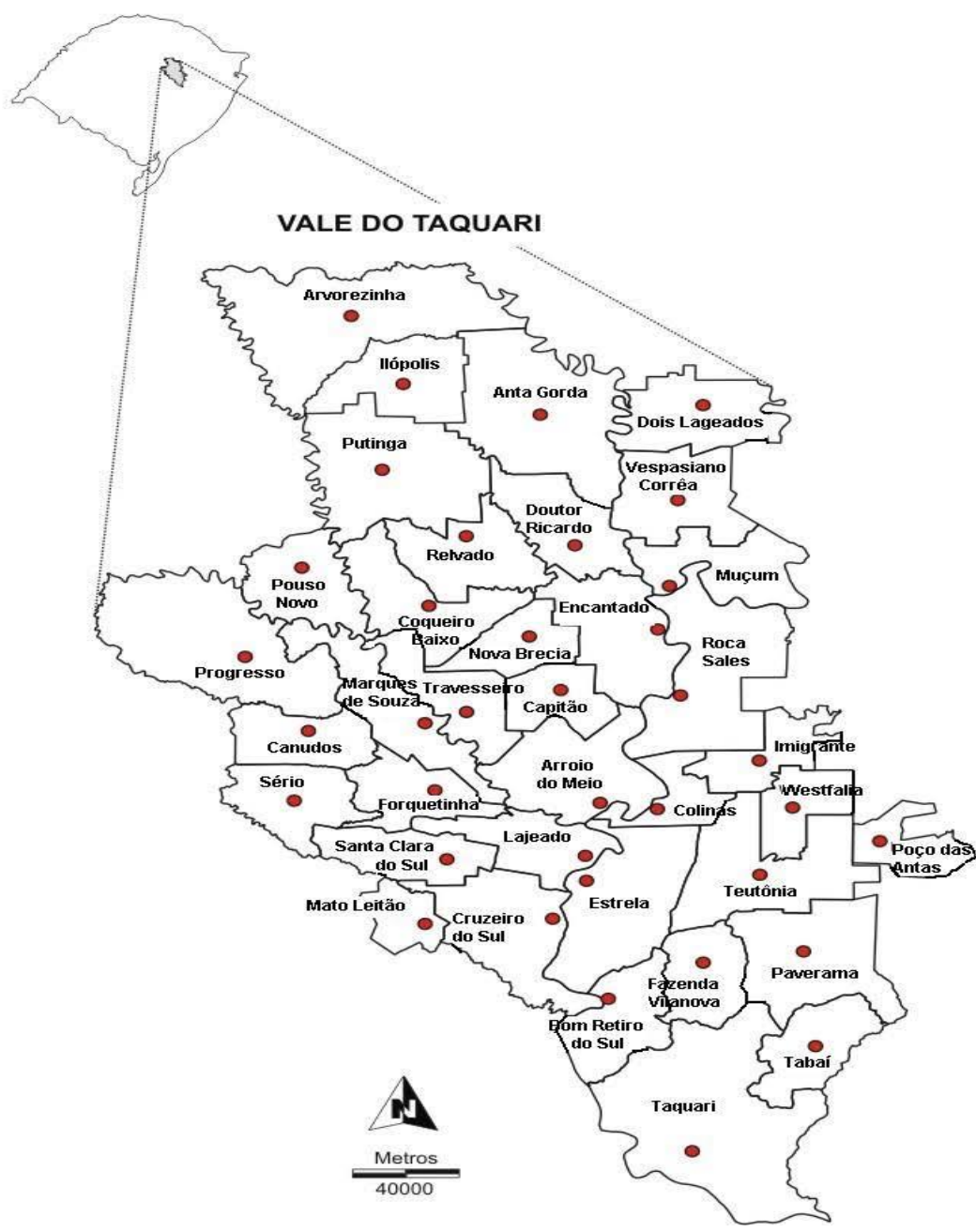

Fonte:https://www.researchgate.net/figure/Figura-1-Mapa-de-localizacao-do-Vale-do-Taquari _fig1_277050711

Dos 37 municípios vinculados à $16^{\text {a }} \mathrm{CRS}$, foi possível analisar as práticas de descarte de medicamentos e correlatos em 16 (44,4\%). A maioria dos profissionais que responderam ao questionário é do sexo feminino ( $n=10 ; 62,5 \%)$, possui curso de graduação na área da saúde ( $n=14 ; 87,5 \%)$, e suas idades variaram entre 26 a 56 anos.

A maioria dos municípios apresentam população inferior a 10.000 habitantes ( $n=14 ; 87,5 \%$ ) e apenas uma US ( $n=13 ; 81,3 \%$ ), sendo nesta realizada a dispensação de medicamentos, absorvendo toda a demanda da população. Para a dispensação de medicamentos pela rede pública dos municípios existem critérios estabelecidos, 
sendo que em $100,0 \%$ é solicitada a prescrição médica, contudo prescrições provindas da rede particular e convênios são aceitas em metade dos municípios.

Em todos os municípios analisados $(100,0 \%)$ há contrato com empresa terceirizada específica para a destinação dos medicamentos vencidos nas US. O descarte de lancetas, seringas para aplicação de insulina e tiras reagentes é realizada nas US pelos usuários em $87,5 \%$ dos municípios. Entretanto, em um município (6,3\%) foi relatado que a responsabilidade de descarte é atribuída ao próprio usuário. Ainda, os profissionais relataram que os usuários são informados sobre o descarte dos produtos que estão levando ( $n=13$ municípios; 81,3\%), fato que denota a preocupação dos entrevistados com a temática.

A carência de informações e campanhas de educação em saúde quanto ao descarte de medicamentos vencidos ou em desuso pela população resulta em descarte inadequado desses resíduos. Para Gasparini et al. (2011), a falta de informação é o ponto norteador para a prática inadequada de descarte de medicamentos. O autor, ainda, ressalta a falta de divulgação e de campanhas de educação ambiental abordando os males causados pelos medicamentos ao meio ambiente quando descartados em lixos domésticos, pias e vaso sanitário, além disso traz a discussão sobre a carência de pontos de coleta (GASPARINI; GASPARINI; FRIGIERI, 2011).

No estudo proposto, segundo relato dos profissionais responsáveis pela $A F$, verificou-se que existem locais adequados para a prática do descarte pela população em $75,0 \%$ dos municípios, sendo estes localizados juntamente a farmácia $(75,0 \%)$ ou em local próximo (16,7\%). As orientações e campanhas sobre a importância do tema são realizadas em $81,3 \%$ dos municípios, sendo elas, na maioria das vezes, realizadas pelos agentes comunitários de saúde (ACS) (69,2\%). Também foram citadas outras estratégias, como orientações no momento da dispensação dos medicamentos e correlatos $(61,5 \%)$, distribuição de folders nas US $(46,2 \%)$, discussão do tema em grupos de saúde e em reuniões com a comunidade $(30,8 \%)$ e, ainda, quando possível, em feiras de saúde (7,7\%). 
O PGRSS deve ser elaborado em todos os estabelecimentos de saúde, públicos e privados, geradores de RSS visando o destino correto como exigência para cumprimento da RDC n. ㅇ 222/2018 da ANVISA. Contudo, apenas 50,0\% das secretarias de saúde participantes do estudo possuem o PGRSS, sendo o mesmo de conhecimento e acessível aos profissionais entrevistados. Ainda, em $75,0 \%$ desses municípios os profissionais responsáveis pela AF participaram da elaboração do PGRSS.

O recolhimento dos medicamentos e correlatos por empresa terceirizada é realizada em periodicidades variáveis, sendo mensalmente em $37,5 \%$ dos municípios e quinzenalmente em $31,3 \%$. A quantidade efetiva recolhida foi categorizada de acordo com o volume ocupado do recipiente específico, verificando-se ocupação em capacidade máxima permitida $(n=6 ; 37,5 \%)$, em metade da capacidade $(n=4 ; 25 \%)$ e em capacidade inferior a $50 \%(n=6 ; 37,5 \%)$. Ainda, analisou-se a origem desses resíduos, observando-se que em $56,2 \%$ dos municípios o coletor é utilizado por toda secretaria de saúde, enquanto em $25,0 \%$ os dados referem-se apenas aos rejeites da US (Tabela 2).

Tabela 2. Características do recolhimento de RSS no âmbito do SUS no Vale do Taquari RS $(n=16)$.

\begin{tabular}{lcc}
\hline Variável & Frequência (n) & Porcentagem (\%) \\
\hline Recolhimento realizado por & & $100,0 \%$ \\
Empresa especializada e terceirizada & 16 & $12,5 \%$ \\
Periodicidade da coleta & & $31,3 \%$ \\
Semanal & 2 & $37,5 \%$ \\
Quinzenal & 5 & $6,3 \%$ \\
Mensal & 6 & $12,4 \%$ \\
Trimestral & 1 & \\
Outra & 2 & $56,2 \%$ \\
RSS originados em & & $25,0 \%$ \\
Secretaria municipal de saúde (SMS) & 9 & $12,5 \%$ \\
Unidade de saúde & 4 & $6,3 \%$ \\
SMS e comunidade & 2 & \\
Farmácia & 1 & \\
\hline
\end{tabular}


A problemática do descarte de resíduos vem ao encontro dos investimentos realizados para aumentar o acesso aos medicamentos, sendo assim, essa ampliação no acesso não garante racionalidade na utilização (FERNANDES, et al; 2020). O uso racional de medicamentos, conforme a OMS (Nairóbi, Quênia, 1985), é considerado quando os usuários recebem o medicamento apropriados para suas condições clínicas, em doses adequadas às suas necessidades individuais, por um período adequado e ao menor custo para si e para a comunidade (BRASIL, 2012).

Desta forma, o conhecimento e empenho dos profissionais da saúde e gestores dos municípios torna-se relevante em todos os sentidos. Conforme discutidos neste estudo ficou evidenciado que todos os municípios do VT apresentam PGRSS e todos os profissionais relatam conhecer e ter acesso ao documento, contudo, apenas em $37,5 \%$ dos municípios o recipiente é usado em sua capacidade máxima. Mais da metade dos municípios participantes do estudo não utilizam a capacidade contratada, gerando custos, indiretamente, para a comunidade. Como opção a ser avaliada para a problemática visualizada, a união dos municípios revendo um plano juntamente com a empresa terceirizada poderia ser considerada, a fim de diminuir desperdícios.

Orientações relacionadas a ações de educação em saúde, precisam assumir papel estratégico dentro das US envolvendo toda equipe. Foi percebido nos questionários respondidos com 69,2\%, que os ACS acabam desempenhando intervenções relevantes na comunidade, sendo a principal fonte de informação. Ressalta-se a importância do envolvimento de todos os profissionais na promoção e educação em saúde, resultando assim, na autonomia do usuário na adesão ao tratamento.

Ficou notório no estudo que nem todos os municípios (61,5\%) informam sobre o descarte de medicamentos e correlatos no momento da dispensação aos usuários, preocupante quanto a resposta de um dos municípios relatando que a dispensação dos correlatos é de responsabilidade do próprio usuário. Problemática que poderia ser resolvida com a divulgação e a realização de capacitações promovendo aos 
profissionais um momento de integração da rede de saúde, possibilitando a abertura para novos campos de atuação dos profissionais e orientações pertinentes aos usuários frequentadores da US correspondente.

Como limitações do estudo, aponta-se a dificuldade de contato com os profissionais responsáveis pela AF dos municípios, questionário online devido a pandemia dificultando a interação com os profissionais e explicações necessárias para as respostas e ainda acreditamos, que por este motivo, alguns dados não foram possíveis ser utilizados pela discrepância de respostas.

\subsection{Panorama do descarte de medicamentos e correlatos no município de Lajeado - RS}

\subsubsection{Conhecimento da população do município de Lajeado - RS sobre o descarte de medicamentos e correlatos}

O questionário disponibilizado de forma online para os munícipes de Lajeado foi acessado por 280 indivíduos, sendo que 277 concordaram com o TCLE e responderam ao mesmo, sendo incluídos na amostra. A idade dos pesquisados variou de 18 a 72 anos, perfazendo média de 40 anos de idade. A amostra foi constituída, em sua maioria, por mulheres $(80,1 \%)$ e indivíduos com ensino superior completo $(48,0 \%)$ ou ensino médio completo $(21,3 \%)$ (Tabela 3$)$.

No presente estudo, observou-se que 98,9\% $(n=274)$ dos participantes possuem medicamentos em suas residências, os quais são armazenados no quarto $(n=135 ; 49,3 \%)$, cozinha $(n=105 ; 38,3 \%)$, banheiro $(n=51 ; 18,6 \%)$ e/ou sala $(n=33$; 12,0\%), entre outros locais (Tabela 3). O hábito de ter uma "farmácia caseira" é uma cultura comum nas residências brasileiras, diversos estudos verificaram que a prática ocorre em mais de $95 \%$ nos domicílios amostrados justificados pela utilização em situações de emergência. Quanto aos locais de guarda, são frequentemente citados os cômodos relacionados nesse estudo (GASPARINI; GASPARINI; FRIGIERI, 2011; 
FERNANDES et al., 2020; RODRIGUES et al., 2020).

Um dos questionamentos realizados foi em relação a sobras de medicamentos, sendo que a maioria dos pesquisados ( $n=235 ; 85,8 \%$ ) afirmou ter sobras em casa. $A$ presença de restos de tratamentos estocados nos domicílios também foi observada em estudo realizado em Curitiba - PR, em que 63,0\% dos participantes relatou o fato (MARQUES; XAVIER, 2018). Os principais motivos relatados para a remanescência foram "embalagens dos medicamentos quando compradas em farmácia ou drogarias, tem quantidade maior que a necessária para o tratamento" ( $n=162 ; 68,9 \%$ e interrupção do uso ao perceber melhora dos sintomas ( $n=80 ; 34,0 \%)$ (Tabela 3). A prática de suspensão do tratamento ao perceber-se melhora dos sintomas pode ser um indicativo de problemas na adesão à terapia farmacológica, o qual impacta na resolutividade e, consequentemente, pode influenciar negativamente na morbimortalidade.

Quando inquiridos sobre o que fazem com as sobras de medicamentos, a maioria dos entrevistados $(n=191 ; 81,3 \%)$ relatou armazená-las a fim de utilizar caso apresente sintomas parecidos e/ou 14,9\% ( $n=35)$ compartilham as mesmas com outras pessoas que mencionam possuir sintomas semelhantes àqueles que levaram ao uso do produto. Alguns entrevistados relataram devolvê-las em farmácias ou US $(\mathrm{n}=64 ; 27,2 \%)$ e, ainda, outros disseram descartá-las de forma inadequada $(\mathrm{n}=26$; 11,1\%) (Tabela 3).

Tabela 3. Informações coletadas junto a amostra populacional do munícipio de Lajeado - RS sobre o descarte de medicamentos $(n=277)$.

\begin{tabular}{lr} 
Variável & Frequência (n) \\
\hline Caracterização da população amostrada $(\mathbf{n = 2 7 7 )}$ & Porcentagem (\%) \\
Sexo & 222 \\
Feminino & 55 \\
Masculino & $19,9 \%$ \\
Faixa etária & 82 \\
18 a 29 anos & 67 \\
30 a 39 anos & \\
40 a 49 anos & 51 \\
50 a 59 anos & \\
60 a 69 anos & 41
\end{tabular}




\section{Escolaridade}

Ensino fundamental incompleto

Ensino fundamental completo

Ensino médio incompleto

Ensino médio completo

Ensino superior incompleto

Ensino superior completo

\begin{tabular}{|c|c|c|}
\hline \multicolumn{3}{|l|}{$\begin{array}{l}\text { Estoque domiciliar de medicamentos }(\mathrm{n}=274) \\
\text { Local(is) de armazenamento dos medicamentos no domicílio }\end{array}$} \\
\hline Banheiro & 51 & $18,6 \%$ \\
\hline Cozinha & 105 & $38,3 \%$ \\
\hline Quarto & 135 & $49,3 \%$ \\
\hline Sala & 33 & $12,0 \%$ \\
\hline Outro cômodo & 10 & $3,6 \%$ \\
\hline \multicolumn{3}{|l|}{ Sobras de medicamentos } \\
\hline Não ocorre & 39 & $14,2 \%$ \\
\hline Ocorre & 235 & $85,8 \%$ \\
\hline \multicolumn{3}{|l|}{ Motivo da sobra de medicamentos $(n=235)$} \\
\hline Embalagem com quantidade superior a necessária & 162 & $68,9 \%$ \\
\hline Interrupção do tratamento & 80 & $34,0 \%$ \\
\hline Outros motivos & 23 & $9,8 \%$ \\
\hline \multicolumn{3}{|l|}{ Destino das sobras de medicamentos $(n=235)$} \\
\hline Armazenamento no domicílio para uso posterior & 191 & $81,3 \%$ \\
\hline Compartilhamento com familiares ou conhecidos & 35 & $14,9 \%$ \\
\hline Devolução na farmácia ou US & 64 & $27,2 \%$ \\
\hline Descarte no lixo doméstico & 26 & $11,1 \%$ \\
\hline \multicolumn{3}{|l|}{ Vencimento do prazo de validade de medicamentos } \\
\hline Não ocorre & 47 & $17,2 \%$ \\
\hline Ocorre & 227 & $82,8 \%$ \\
\hline \multicolumn{3}{|l|}{ Local de descarte de medicamentos vencidos $(n=227)$} \\
\hline Drogarias/farmácias/US & 113 & $49,8 \%$ \\
\hline Lixo doméstico & 96 & $42,3 \%$ \\
\hline Rede de esgoto (pia e/ou vaso sanitário) & 44 & $19,4 \%$ \\
\hline \multicolumn{3}{|l|}{ Local de descarte da embalagem primária $(\mathrm{n}=227)$} \\
\hline Drogarias/farmácias/US & 83 & $36,6 \%$ \\
\hline Lixo doméstico & 145 & $63,9 \%$ \\
\hline \multicolumn{3}{|l|}{ Local de descarte da embalagem secundária e bula $(n=227)$} \\
\hline Drogarias/farmácias/US & 12 & $5,3 \%$ \\
\hline Lixo doméstico & 217 & $94,7 \%$ \\
\hline \multicolumn{3}{|c|}{ Informação sobre o descarte de medicamentos vencidos ou/em desuso na farmácia ou US (n=277) } \\
\hline Não recebeu & 169 & $61,0 \%$ \\
\hline Recebeu & 108 & $39,0 \%$ \\
\hline
\end{tabular}


estudo de abrangência nacional realizado pelo Instituto Datafolha por solicitação do CFF, em 2019, direcionado ao uso de medicamentos. No estudo nacional verificou-se que a maioria dos indivíduos entrevistados $(61,0 \% ; n=2074)$ afirmou se automedicar, empregando nessa prática medicamento anteriormente utilizado. Ainda, 47,0\% dos usuários que participaram da pesquisa relataram utilizar medicamentos quando algum conhecido, como amigos, vizinhos ou familiares, Ihe indica ou até mesmo oferece para uso, assim como $44,0 \%$ que acabam utilizando, pois, alguém próximo obteve resultado positivo (CFF, 2019).

Na mesma pesquisa, também se observou que $44,0 \%$ dos entrevistados já deixaram de utilizar os medicamentos prescritos antes de finalizar o tratamento, isto justificado pela própria percepção de que o medicamento era muito forte ou por ocorrer reações indesejadas. Ainda, 19,0\% dos entrevistados, quando se deparam com dúvidas seja em relação ao tratamento ou sobre algum medicamento, param de fazer o uso, não procurando esclarecer dúvidas, ocasionando sobras nas residências (CFF, 2019).

O hábito de usar medicamentos sem prescrição médica corrobora com a prática do uso irracional de medicamentos. Na região Sul do Brasil, conforme pesquisa do CFF, 29,0\% dos entrevistados não utilizam medicamentos por conta própria, ou seja, não são adeptos da prática da automedicação. No presente estudo, verificou-se que a grande maioria dos pesquisados utiliza sobras de medicamentos na automedicação, seja para si $(81,3 \%)$ e/ou indicando para terceiros $(14,9 \%)$.

Ramos (2017) aborda em seu estudo possíveis condutas quanto aos problemas relativos à quantidade nas embalagens dos medicamentos e $23,2 \%$ dos entrevistados mencionaram que a venda fracionada de medicamentos, levando em consideração o tempo e quantidade de medicamentos ao tratamento proposto, seria uma alternativa pois diminuiria as sobras, vencimento e consequentemente 0 descarte. Sem dúvida, o fracionamento é uma estratégia para promoção do uso racional de medicamentos, que diminuiria o acúmulo de produtos nos domicílios, evitando automedicação e, também, casos de intoxicação. 
A proposta de realização de fracionamento de medicamentos é antiga, teve início com discussões no Decreto no 793/93 onde foi, entre outros assuntos, instituída a proposta de verificar a possibilidade de dispensar medicamentos fracionados em farmácias e drogarias. Logo após, essa possibilidade foi simplificadamente regulamentada pela Portaria SVS/MS № 112 de novembro de 1993, porém somente comprimidos, drágeas, supositórios e ampolas poderiam ser fracionados sob responsabilidade do profissional farmacêutico a realização (OLIVEIRA, 2009).

Algumas alterações e adequações necessitaram ser realizadas até a criação da RDC 80/2006, ANVISA que dispõe que as farmácias e drogarias poderão fracionar medicamentos desde que as embalagens sejam especialmente desenvolvidas para essa finalidade. Porém, o que se percebe é que poucos laboratórios aderiram a esta prática, pois nem sempre os medicamentos são oferecidos em embalagens fracionáveis (MURAKAMI; NETO; SILVA; 2012). Atualmente estão disponíveis 549 especialidades farmacêuticas passíveis de fracionamento no mercado brasileiro (ANVISA, 2020).

Outra problemática relatada pela maioria dos pesquisados ( $n=227 ; 82,8 \%$ ) é a expiração do prazo de validade dos medicamentos, visto que além da perda econômica, há impacto ambiental significativo, pois, muitos usuários relataram descartar esses produtos parcialmente ou totalmente no lixo doméstico $(42,3 \%)$ ou na rede de esgoto (pia e/ou vaso sanitário) (19,4\%). Porém, aproximadamente metade dos entrevistados $(49,8 \%)$ despreza os rejeites de forma adequada em drogarias/farmácias ou US (Tabela 3).

Quanto a embalagem primária (blísteres), a maioria dos pesquisados $(63,9 \%)$ relatou descartar no lixo doméstico (Tabela 3). Todos medicamentos que apresentem risco químico, como aqueles constantes na Portaria MS n. ํ 344/1998, hormônios, antineoplásicos, antimicrobianos, entre outros (Figura 2), devem possuir encaminhamento específico para o descarte final, incluindo a embalagem primária. $\mathrm{O}$ grande problema é a realização desta diferenciação pela população, que pelo pouco 
conhecimento acaba descartando todos os blísteres no lixo doméstico, acarretando contaminação do solo e água. Quanto a embalagem secundária e bula dos medicamentos, $94,7 \%$ dos respondentes afirmaram realizar o descarte no lixo doméstico, porém 5,3\% dos participantes relataram levar os mesmos para descarte na farmácia ou US (Tabela 3).

Figura 2. Manejo de Medicamentos Vencidos

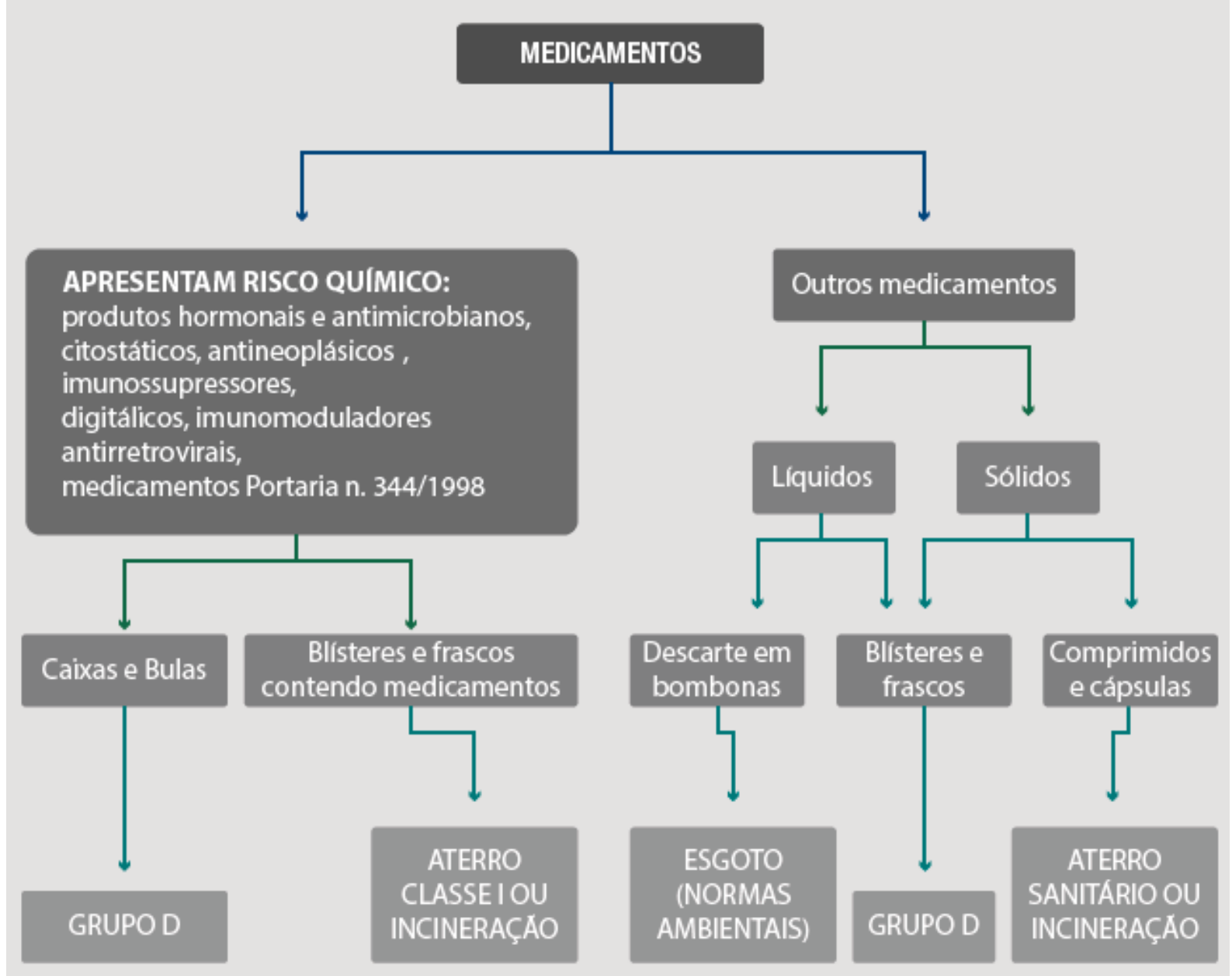

Fonte: ASSISTÊNCIA FARMACÊUTICA NO BRASIL: Política, Gestão e Clínica - Logística de Medicamentos, 2016.

A insuficiência de conhecimento em relação ao tema de resíduos sólidos de saúde fica evidenciada pelos dados apresentados e pode se relacionar ao fato que $61,0 \%$ dos participantes deste estudo relataram que nunca foram informados sobre a maneira correta de realizar o descarte de medicamentos vencidos ou em desuso 
(Tabela 3), o que também foi percebido no estudo de Aurélio (2015) e no de Marques (2018). Em estudo realizado com alunos de cursos de graduação e técnicos situados na região de Paulínia - SP, verificou-se que $98,0 \%$ dos entrevistados afirmaram não ter conhecimento de campanhas públicas de descarte de medicamentos nas residências, e, ainda, 92,0\% não sabem onde descartar medicamentos vencidos ou em desuso (PINTO et al., 2014).

Nos estudos realizados por Aurélio (2015), Marques (2018) e pelo CFF (2019), o descarte de medicamentos no lixo doméstico prevaleceu entre as respostas dos entrevistados. Contudo, no presente estudo verificou-se que $49,8 \%$ dos indivíduos realiza o descarte de forma adequada. Na pesquisa do CFF, ao analisar-se as regiões do País separadamente, foi possível verificar que a região Sul obteve resultado diferente das demais regiões, identificando-se que $35,0 \%$ das pessoas entrevistadas relatam descartar os medicamentos em farmácias e postos de saúde, o que corrobora, em parte, com o resultado encontrado em Lajeado. Um fator que pode ter contribuído para uma parcela maior da população estar realizando o descarte de medicamentos vencidos e/ou em desuso de forma adequada no município é a presença de coletoras para esses resíduos nas US.

\subsubsection{Promoção do uso racional de medicamentos e de práticas ambientalmente corretas através da educação em saúde: parceria entre Universidade e Poder Público}

A Farmácia-Escola (FE) é uma parceria entre a Prefeitura Municipal de Lajeado/RS e a Universidade do Vale do Taquari - UNIVATES, com auxílio do Ministério Público Federal. Como objetivo principal propõe-se a prestar atendimento humanizado a população, ofertando serviços qualificados na área da Assistência Farmacêutica, a fim de melhorar a qualidade de vida dos usuários, conforme suas especificidades biopsicossociais. Atividades voltadas a promoção da saúde da comunidade lajeadense são realizadas, além de ser local para a formação de profissionais de saúde e estudantes para atuarem nos mais diversos municípios disseminando os conhecimentos adquiridos. 
No ano de 2012, teve início o projeto de concepção e construção de uma coletora para descarte de medicamentos vencidos ou em desuso, a qual se encontra disponível para os usuários na FE desde aquele ano. O desenvolvimento do projeto da coletora constituiu-se num processo democrático, no qual os colaboradores da FE participaram ativamente, através de opiniões, sugestões e com muita criatividade, de modo que o objeto final aliasse praticidade, visibilidade, segurança e baixo custo (Figura 3) (MEEP, 2013).

Figura 3. imagem da primeira coletora

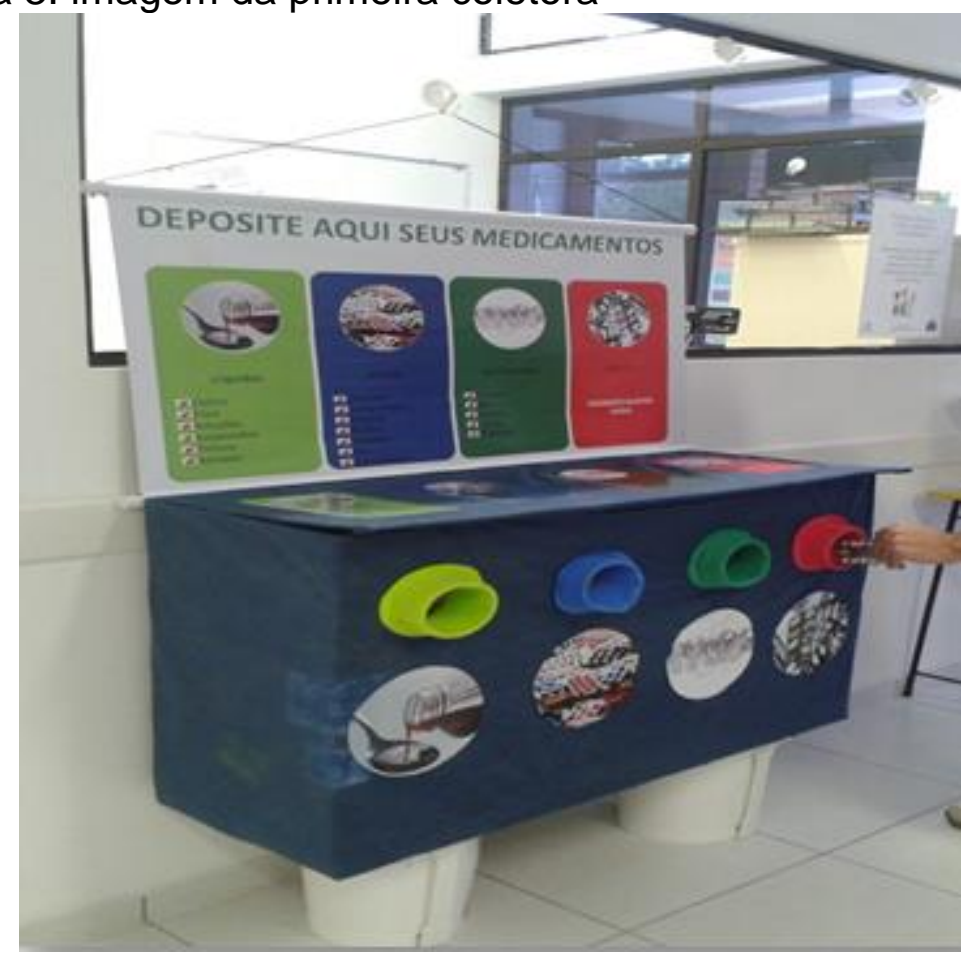

Fonte: Da autora.

A quantidade de medicamentos dispensados mensalmente, somado a leituras, despertou na equipe da FE uma preocupação: "os usuários descartam os medicamentos inadequadamente, jogando-os em pia, vaso sanitário, lixo comum." e uma questão: "o que podemos fazer?". Assim, a partir de debates e discussões em equipe, surgiu a ideia da construção de uma coletora para medicamentos vencidos ou em desuso para que esses produtos armazenados nas residências dos usuários do 
serviço pudessem ter o descarte correto. O principal objetivo da elaboração da coletora e de sua inserção no ambiente da FE foi conscientizar e educar a população para o descarte adequado de rejeites medicamentosos, além de contribuir para a diminuição de possíveis acidentes ambientais (MEEP, 2013).

Os resíduos descartados na coletora, durante o primeiro semestre de 2013, foram caracterizados quantitativamente e qualitativamente. No período foram descartadas 4598 unidades de comprimidos, drágeas ou cápsulas; 46 unidades de produtos semissólidos e 55 frascos de medicamentos líquidos, perfazendo o total de 4699 unidades. Além disso, foram coletados $0,15 \mathrm{~kg}$ de blísteres vazios. A maioria dos produtos descartados $(59,8 \%)$ eram medicamentos apresentados em formas farmacêuticas sólidas e quanto ao tipo similares (49,8\%). Conforme esperado, 76,5\% dos medicamentos descartados estavam com prazo de validade expirado (MEEP, 2013).

Com a disponibilização da coletora na FE, os usuários passaram a serem orientados quanto ao descarte no momento da dispensação e puderam aderir a uma atitude sustentável, contudo essa estratégia não atingia à toda população do município. Desta forma, a partir do ano de 2013, diversas ações voltadas a temática de resíduos sólidos de saúde começaram a ser desenvolvidas pela FE em parceria com as US de Lajeado.

No ano de 2015, teve início o projeto de extensão intitulado "Uso racional de medicamentos e meio ambiente: Conscientizando a comunidade sobre o descarte de medicamentos", envolvendo a Univates e a Prefeitura de Lajeado. A proposta do mesmo era ampliar a cobertura das ações já desenvolvidas sobre o tema, alocando coletoras de medicamentos em cada US com dispensário do município, a fim de facilitar o acesso da comunidade ao dispositivo (BJPS, 2019).

No desenvolvimento do projeto de extensão, um novo protótipo de coletora começou a ser estudado, visando adequar-se a realidade das US. A concepção dos equipamentos baseou-se na segurança, principalmente para crianças, no espaço 
disponível da unidade, assim como, na facilidade de recolhimento dos rejeitos (Figura 4a). A construção dos coletores foi feita em madeira, com bocal em cano de policloroeteno (PVC) e porta superior, fechada por cadeado e adesivada de maneira a identificar o projeto e a finalidade da mesma (Figura 4b). Os coletores construídos foram destinados a 12 unidades de APS do município, as quais apresentam dispensários de medicamentos, assegurando nesses espaços a correta destinação dos resíduos químicos e a racionalidade no uso de medicamentos (BJPS, 2019).

Figura 4. (a) Maquete do dispositivo de segurança utilizados nas coletoras (esquerda); e (b) Coletoras encaminhadas as US (direita).
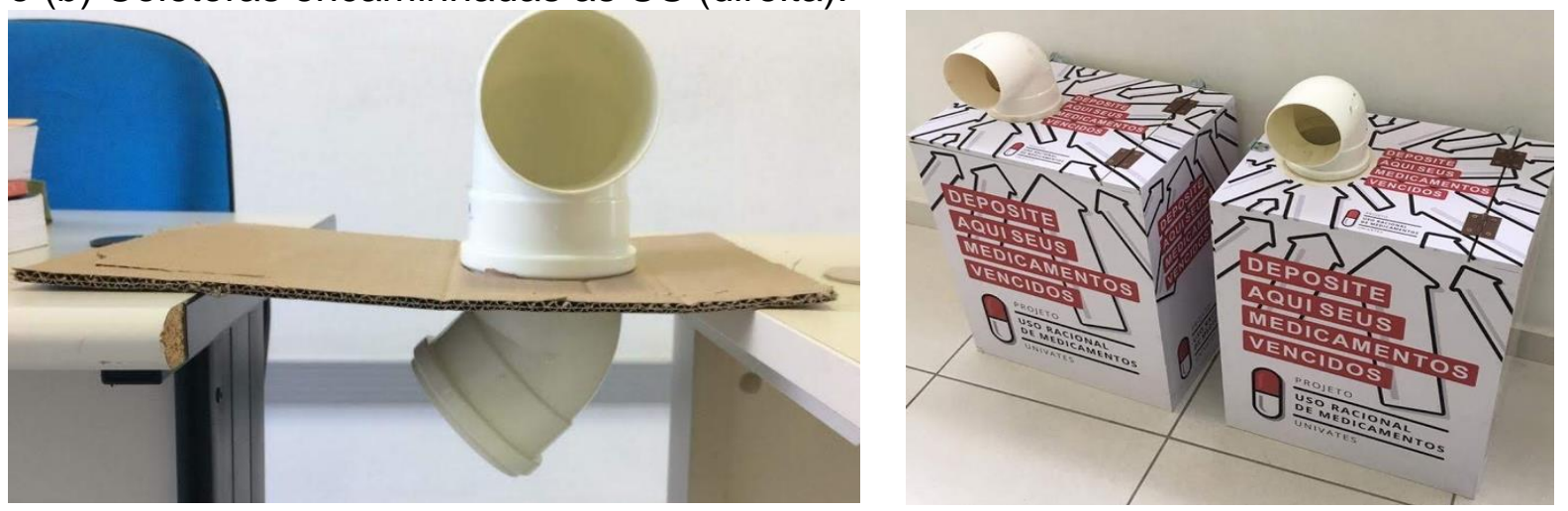

No momento da entrega da coletora nas Unidades de Saúde, juntamente com a coordenação da Unidade foi verificado o melhor local, levando em consideração segurança e acesso conforme disponibilidade do setor. Todas foram alocadas próximas aos dispensários, pois foi percebido juntamente com a equipe, que seria 0 local de maior visibilidade. Após a escolha do local, um pequeno treinamento foi realizado com o profissional responsável pelo dispensário, sendo o mesmo encarregado a ser o multiplicador do conhecimento entre a equipe e usuários. Ainda ficou determinado o fluxo dos resíduos descartados para que, após atingir o volume máximo da coletora, os resíduos armazenados corretamente, em saco conforme legislação, fossem encaminhados para o Almoxarifado Central de Medicamentos que daria o destino final (BJPS, 2019).

Em 2020, as percepções dos colaboradores dos dispensários sobre a inserção da coletora na US foram analisadas, como parte do presente trabalho. Assim, foram 
entrevistados 10 auxiliares administrativos, em sua maioria mulheres $(n=8)$, os quais atuam como auxiliares no dispensário das US de 3 meses a 7 anos.

A periodicidade de encaminhamento dos resíduos para o Almoxarifado Central varia de acordo com a US, sendo relatado envio semanal $(10,0 \%)$, mensal $(50,0 \%)$ ou bimestral $(40,0 \%)$ pelos trabalhadores entrevistados. A implantação da coletora nas US foi vista como positiva por todos os profissionais, sendo alguns relatos descritos no Quadro 1. Outro aspecto questionado foi a interação da população com a coletora, ao que apenas um trabalhador relatou não ter afetado no descarte dos medicamentos, conforme colocações expostas no Quadro 1. De uma maneira geral, o real objetivo da colocação de uma coletora de medicamentos nas US foi entendido pelos colaboradores, pois, em sua unanimidade, a resposta foi realizar o descarte correto para diminuir impactos ao meio ambiente.

Quadro 1.Percepções dos colaboradores dos dispensários sobre a implantação das coletoras nas US do município de Lajeado - RS

Questão: O que achou da iniciativa?

"De extrema importância, tanto por questões sanitárias/saúde como ambientais."

"Achei ótima, pois chama a atenção da população que às vezes não sabia a forma correta de descarte."

"Ótima."

"Boa, pois possibilita o descarte correto."

"Um excelente trabalho, pois podemos observar o quanto a população estoca medicação em casa."

"Achei importante. A caixa faz com que os pacientes questionem sobre a importância de descarte correto de medicamentos."

“Excelente."

"Ótimo, pois tem um lugar específico para o descarte dos medicamentos."

"Sustentável, muito importante nos dias de hoje."

"Boa." 
Questão: Percebeu alguma interação da população com a coletora? Que tipo de interação?

Participação ativa no descarte de medicamentos e embalagens.

Muitos pacientes ao ver a caixa se viram na oportunidade de um descarte adequado.

Mais cuidado com a medicação. Se sobra ou se o médico troca, o paciente traz de volta.

Algumas pessoas sim, trazem o material e já vão direto na caixa.

A população reagiu de uma forma bem positiva, era o que necessitavam para que pudessem ter um destino correto.

A procura pelo descarte de medicação aumentou consideravelmente.

A população recebeu a iniciativa positivamente.

Bastante interação no descarte correto de resíduos de medicamentos.

Pouca, geralmente recebo a medicação e depois coloco na caixa.

Sim, mas de forma negativa, pois eles colocam de tudo na caixa como por exemplo celular.

\subsubsection{Caracterização dos resíduos descartados nas coletoras de medicamentos vencidos e/ou em desuso do município de Lajeado - RS}

A implantação das coletoras nas US possibilitou a realização de um diagnóstico sobre o descarte de medicamentos vencidos ou/em desuso no município de Lajeado. No período amostrado, o qual abrangeu o ano de 2019, foram contabilizados um total de 178.564 unidades de produtos descartados nas coletoras das US $(n=12)$ e da FE $(n=1)$, além de $220 \mathrm{~kg}$ de embalagens primárias.

As coletoras parecem estar cumprindo com a sua função quando é possível realizar um comparativo do ano de 2013 onde foi instalada a primeira coletora e assim o assunto começou a ser inserido nos atendimentos realizados e abordado com os usuários e ainda, no ano de 2019, com a ampla inserção das coletoras em todas US 
do município de Lajeado. Considerando o período de coleta de um ano, os produtos descartados na FE no ano de 2013, contabilizaram 4.699 unidades e no ano de 2019 o aumento é significativo, contabilizando 57.076 produtos descartados corretamente pela população exclusivamente na FE.

Ao analisar-se os resíduos, observou-se que além de medicamentos ( $n=177.956)$, incluindo aqueles de uso veterinário, foram descartados suplementos alimentares $(n=448)$, produtos correlatos $(n=143)$ e outros produtos $(n=17)$. No presente estudo, as formas de apresentação foram avaliadas, havendo predomínio daqueles em forma sólida ( $n=176.013 ; 98,6 \%$ ). Em uma visão geral dos produtos descartados e como é esperado, o descarte de produtos com o prazo de validade expirado representou $52,1 \%$ (Tabela 4 ).

Tabela 4. Caracterização dos RSS descartados nas coletoras disponíveis nas US do município de Lajeado - RS, no ano de 2019 ( $n=178.564)$.

\begin{tabular}{lrr}
\hline Variável & Frequência (n) & Porcentagem (\%) \\
\hline Categoria do produto & & \\
Medicamentos & 177.956 & $99,7 \%$ \\
$\quad$ Pertencentes a REMUME & 134.300 & $75,2 \%$ \\
$\quad$ Não pertencentes a REMUME & 43.593 & $24,4 \%$ \\
$\quad$ De uso veterinário & 63 & $0,04 \%$ \\
Produtos correlatos & 448 & $0,25 \%$ \\
Suplementos alimentares & 143 & $0,08 \%$ \\
Outros produtos & 17 & $0,01 \%$ \\
Validade dos produtos & & \\
Válidos & 85.545 & 47,9 \\
Prazo de validade expirado & 93.019 & 52,1 \\
Apresentação dos produtos quanto à forma & & \\
Sólida & 176.013 & 98,6 \\
Líquida & 2.061 & 1,1 \\
Semissólida & 490 & 0,3 \\
\hline
\end{tabular}

A maior parte dos medicamentos descartados ( $n=134.300 ; 75,2 \%)$ nas coletoras constam na REMUME, sendo que $47,9 \%$ encontravam-se com prazo de validade vigente (Tabela 4). O impacto econômico foi um dos dados analisados e com resultados relevantes ao presente estudo, visando verificar os custos dos medicamentos que são descartados pelos usuários. Os medicamentos constantes na 
REMUME perfizeram $R \$ 30.539,81$, sendo que os produtos dentro do prazo de validade representaram $34,3 \%$, o que equivale a $R \$ 10.462,97$ (Tabela 5). Os valores tornam-se ainda mais relevantes quando, conforme 0 índice de desenvolvimento humano (IDH) da cidade de Lajeado, são repassados $\mathrm{R} \$ 9,62$ por habitante/ano para compra de medicamentos (IBGE, 2018). O desperdício com produtos descartados corresponde ao valor aplicado anualmente para atender 3.175 habitantes, conhecer estes custos é fundamental para estabelecer critérios de gestão dentro da rede de saúde.

Tabela 5. Caracterização dos medicamentos pertencentes a REMUME descartados nas coletoras disponíveis nas US do município de Lajeado - RS, no ano de 2019 $(n=134.300)$.

\begin{tabular}{lrr} 
Variável & Frequência (\%) & Custo em reais (\%) \\
\hline Validade dos medicamentos & $69.153(51,5 \%)$ & $10.462,97(34,3 \%)$ \\
$\quad$ Válidos & $65.147(48,5 \%)$ & $20.076,84(65,7 \%)$ \\
$\quad$ Prazo de validade expirado & $134.300(100,0 \%)$ & $30.539,81(100,0 \%)$ \\
Total & $13 \%$ \\
\hline
\end{tabular}

Além do impacto econômico, a análise das classes dos medicamentos descartados gera preocupação adicional, uma vez que a maioria constitui-se de fármacos de uso contínuo, indicando possíveis falhas na adesão ao tratamento. Dos $178.564(100,0 \%)$ medicamentos descartados, 176.876 (99,0\%) foram classificados pelo código ATC (Tabela 6). Os fármacos que atuam no Trato Alimentar e Metabolismo, no Sistema Cardiovascular e no Sistema Nervoso, corresponderam, respectivamente, a $18,3 \%, 36,3 \%$ e $18,8 \%$ dos medicamentos analisados.

O estudo demonstrou variáveis de classes farmacológicas com viés preocupante, os medicamentos descartados são correspondentes ao trato alimentar e metabolismo e destes $18,6 \%$ presentes na REMUNE onde $10,1 \%$ é referido aos fármacos utilizados no tratamento de diabetes (Tabela 6). Para o sistema cardiovascular, $44,4 \%$ dos medicamentos constavam na REMUME e todos, classe $\mathrm{A}$ e C, dispensados nas US do município, medicamentos estes prescritos para tratamento de uso contínuo, o que nos traz a preocupação de não adesão medicamentosa ao tratamento proposto, troca de medicamentos pelo prescritores e 
possíveis reações adversas que direcionam ao abandono do tratamento.

Tabela 6. Distribuição dos medicamentos descartados quanto ao grupo farmacológico de acordo com segundo nível da ATC $(n=134208)$.

\begin{tabular}{|c|c|c|c|c|c|c|}
\hline \multirow{3}{*}{ GRUPO FARMACOLÓGICO } & \multicolumn{6}{|c|}{ MEDICAMENTOS } \\
\hline & \multicolumn{2}{|c|}{ REMUME } & \multicolumn{2}{|c|}{$\begin{array}{c}\text { NÃO } \\
\text { REMUME }\end{array}$} & \multicolumn{2}{|c|}{ TOTAL } \\
\hline & $\mathbf{n}$ & $\%$ & $\mathbf{n}$ & $\%$ & $\mathrm{n}$ & $\%$ \\
\hline A - TRATO ALIMENTAR E METABOLISMO & 24971 & 18,61 & 7423 & 17,40 & 32394 & 18,31 \\
\hline A01 - Preparações para o estômago & & & 8 & 0,02 & 8 & 0,00 \\
\hline A02 - Agentes para tratamento de alterações causadas por ácidos & 4322 & 3,22 & 627 & 1,47 & 4949 & 2,80 \\
\hline A03 - Agentes contra problemas funcionais do estômago e intestine & 2009 & 1,50 & 561 & 1,31 & 2570 & 1,45 \\
\hline A04 - Antieméticos e antinauseantes & & & 658 & 1,54 & 658 & 0,37 \\
\hline A05 - Terapia biliar e hepática & & & 4 & 0,01 & 4 & 0,00 \\
\hline $\begin{array}{l}\text { A06 - Laxantes } \\
\text { A07 - Antidiarreicos, anti-inflamatórios intestinais e agentes anti- } \\
\text { infecciosos }\end{array}$ & 44 & 0,03 & 329 & 0,57 & 329 & 0,19 \\
\hline A08 - Preparações antiobesidade, excluindo produtos dietéticos & & & 106 & 0,25 & 106 & 0,06 \\
\hline A09 - Digestivos, incluindo enzimas & & & 77 & 0,18 & 77 & 0,04 \\
\hline A10 - Fármacos usados no diabetes & 13556 & 10,10 & 2570 & 6,02 & 16126 & 9,12 \\
\hline A11 - Vitaminas & & & 1635 & 3,83 & 1635 & 0,92 \\
\hline A12 - Suplementos minerais & 5040 & 3,76 & 604 & 1,42 & 5644 & 3,19 \\
\hline B - SANGUE E ÓRGÃOS FORMADORES DO SANGUE & 11488 & 8,56 & 1166 & 2,73 & 12654 & 7,15 \\
\hline B01 - Agentes antitrombóticos & 7768 & 5,79 & 741 & 1,74 & 8509 & 4,81 \\
\hline B02 - Anti-hemorrágicos & & & 88 & 0,21 & 88 & 0,05 \\
\hline B03 - Antianêmicos & 3720 & 2,77 & 337 & 0,79 & 4057 & 2,29 \\
\hline C - SISTEMA CARDIOVASCULAR & 59566 & 44,38 & 4700 & 11,02 & 64266 & 36,33 \\
\hline C01 - Terapia cardíaca & 2671 & 1,99 & 827 & 1,94 & 3498 & 1,98 \\
\hline C02 - Anti-hipertensivo & 1246 & 0,93 & 225 & 0,53 & 1471 & 0,83 \\
\hline C03 - Diuréticos & 14249 & 10,62 & 383 & 0,90 & 14632 & 8,27 \\
\hline C04 - Vasodilatadores periféricos & & & 23 & 0,05 & 23 & 0,01 \\
\hline C05 - Vasoprotetores & & & 388 & 0,91 & 388 & 0,22 \\
\hline C07 - Agentes betabloqueadores & 7167 & 5,34 & 1088 & 2,55 & 8255 & 4,67 \\
\hline C08 - Bloqueador de canal de cálcio & 5406 & 4,03 & 137 & 0,32 & 5543 & 3,13 \\
\hline C09 - Fármacos que atuam no sistema renina angiotensina & 18501 & 13,79 & 460 & 1,08 & 18961 & 10,72 \\
\hline C10 - Fármacos redutores dos lipídeos & 10326 & 7,69 & 1169 & 2,74 & 11495 & 6,50 \\
\hline D - Dermatológicos & 175 & 0,13 & 445 & 1,04 & 620 & 0,35 \\
\hline D01 - Antifúngicos para uso dermatológico & 26 & 0,02 & 73 & 0,17 & 99 & 0,06 \\
\hline D03 - Preparações para o tratamento de feridas e úlceras & & & 17 & 0,04 & 17 & 0,01 \\
\hline D04 - Antipruriginosos, incluindo anti-histamínicos, anestésicos, etc & & & 128 & 0,30 & 128 & 0,07 \\
\hline D06 - Antibióticos e quimioterápicos para uso dermatológico & 35 & 0,03 & 52 & 0,12 & 87 & 0,05 \\
\hline D07 - Corticosteroides em preparações dermatológicas & 35 & 0,03 & 141 & 0,33 & 176 & 0,10 \\
\hline D08 - Antisépticos e desinfetantes & 74 & 0,06 & 19 & 0,04 & 93 & 0,05 \\
\hline D09 - Curativos & 5 & 0,00 & & & 5 & 0,00 \\
\hline
\end{tabular}


D10 - Preparações antiacne

D11 - Outras preparações dermatológicas

\section{G - Sistema geniturinário e hormônios sexuais}

G01 - Anfi-infecciosos e antissépticos ginecológicos

G02 - Outros ginecológicos

G03 - Hormônios sexuais e moduladores do sistema genital

G04 - Produtos urológicos

H - HORMÔNIOS DE USO SISTÊMICO, EXCLUINDO

HORMÔNIOS SEXUAIS E INSULINA

H02 - Corticosteroides de uso sistêmico

H03 - Terapia tireoidiana

\section{J - ANTI-INFECCIOSOS PARA USO SISTÊMICO}

J01 - Antibacterianos de uso sistêmico

J02 - Antimicóticos de uso sistêmico

J05 - Antivirais de uso sistêmico

L - AGENTES ANTINEOPLÁSICOS E IMUNOMODULADORES

L01 - Agentes antineoplásicos

L03 - Imunoestimulantes

L04 - Imunossupressores

\section{M - SISTEMA MUSCULOESQUELÉTICO}

M01 - Anti-inflamatórios e antirreumáticos

M03 - Relaxantes Musculares

M04 - Antigotosos

M05 - Fármacos para tratamento de doenças ósseas

M09 - Outros fármacos para desordens do sistema

musculoesquelético

\author{
N - SISTEMA NERVOSO \\ N01 - Anestésicos \\ N02 - Analgésicos \\ N03 - Antiepiléticos \\ N04 - Antiparkinsonianos \\ N05 - Psicolépticos \\ N06 - Psicoanalépticos \\ N07 - Outros fármacos que atuam sobre o SN (contra a vertigem) \\ P - ANTIPARASITÁRIOS, INSETICIDAS E REPELENTES \\ P01 - Antiprotozoários \\ P02 - Anti-helmínticos \\ P03 - Ectoparasiticidas, incluindo escabicidas, inseticidas e \\ repelentes

\section{R - SISTEMA RESPIRATÓRIO} \\ R01 - Preparações nasais \\ R03 - Agentes para problemas obstrutivos das vias respiratórias \\ R05 - Preparações para tosse e resfriados \\ R06 - Anti-histamínico de uso sistêmico
}

\section{S - ÓRGÃOS SENSORIAIS}

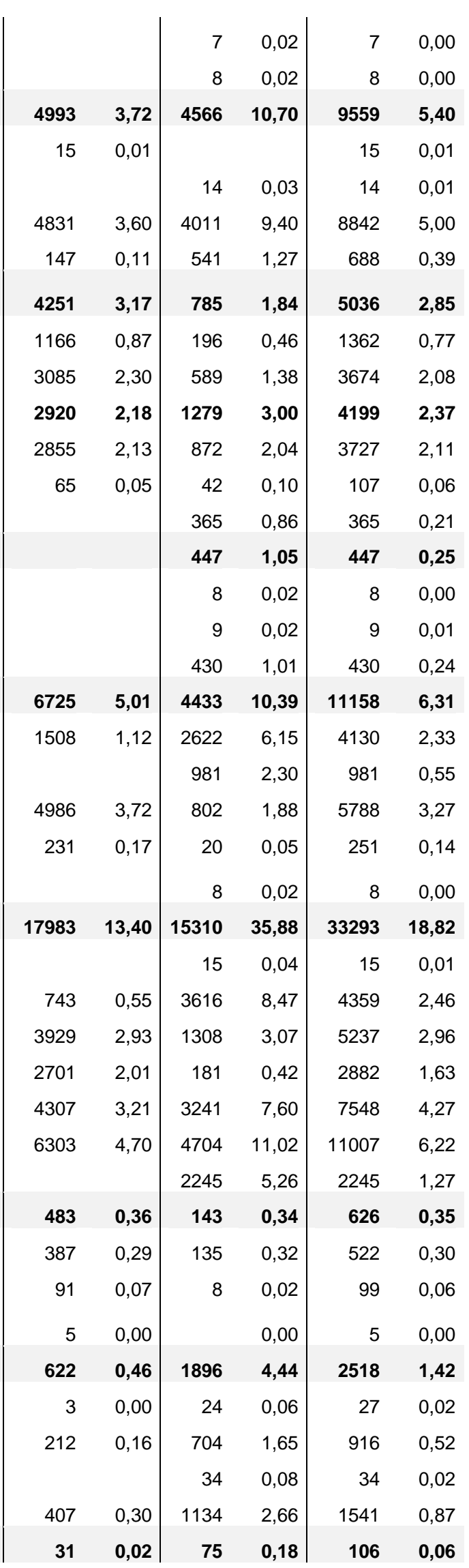


* Medicamentos que não apresentam classificação ATC: 92 pertencentes a REMUME (fitoterápicos); 925 não pertencentes à REMUME (913 fitoterápicos + 12 homeopáticos).

Os fármacos utilizados no tratamento de diabetes mellitus, correspondendo neste estudo em 10,1\% representam uma importante carga financeira em razão dos gastos com insulina, antidiabéticos orais e outros medicamentos essenciais, impactando nos sistemas de saúde e com possíveis consequências a longo prazo. Consequentemente com maior utilização dos serviços de saúde, perda de produtividade e cuidados prolongados para tratar suas complicações crônicas, como cegueira, insuficiência renal, problemas cardíacos, pé diabético e impactos relevantes e difíceis de quantificar como ansiedade e perda da qualidade de vida do usuário e familiares (SBD, 2017).

Indivíduos com diabetes apresentam maiores taxas de hospitalizações em comparação com os que não têm diabetes, além de maior duração da hospitalização para um problema de saúde comum. Os gastos com indivíduos portadores desta patologia são de duas a três vezes maiores do que aqueles sem a doença. No Brasil, no ano de 2015, foi avaliado um custo médio de US $\$ 22$ bilhões, com projeção de US\$ 29 bilhões para 2040 para tratamentos de usuários diabéticos (SBD, 2017). Com esse custo elevado, o diabetes é um desafio para os sistemas de saúde e um obstáculo para o desenvolvimento econômico sustentável (IDF, 2015).

Quanto ao sistema cardiovascular $(44,4 \%)$ classe predominante no estudo, as consequências da não adesão ao tratamento proposto são equivalentes aos usuários portadores de diabetes mellitus. A hipertensão não tratada pode gerar impacto relevante quanto a qualidade de vida e interações sociais, os principais relatos em estudos são afastamento do trabalho, dependência total ou parcial na realização de atividades do cotidiano, dificuldades de locomoção, gastos com assistência médica, afastamento do convívio social e lazer; perda da qualidade de vida e problemas familiares (SBC, 2016). 
No Brasil, estimativas da Sociedade Brasileira de Cardiologia (SBC) apontam que 36 milhões de indivíduos adultos (32,5\%) possuem diagnóstico de doenças do sistema cardiovascular e destes mais de $60 \%$ correspondem ao público idoso, refletindo direta ou indiretamente em $50 \%$ das mortes pela patologia. Estudos norteamericanos ainda acentuam a problemática salientando que a hipertensão arterial sistêmica (HAS) é responsável por $45 \%$ das mortes cardíacas e $51 \%$ das mortes decorrentes de acidente vascular encefálico (SBC, 2016).

Orientações e escuta ativa incentivam a adesão ao tratamento medicamentoso principalmente para obtenção de melhor qualidade de vida visando minimizar a morbimortalidade da população com hipertensão, além de possibilitar uma diminuição do impacto econômico, como foi possível verificar neste trabalho é a classe farmacológica que apresentou alta taxa de descarte $(44,4 \%)$ dentro do período estudado. Em estudo realizado para verificar a adesão a terapia anti-hipertensiva ficou evidenciado que em $37,0 \%$ dos casos, os pacientes com doença cardiovascular não aderem à terapia medicamentosa sendo necessário ampliar a discussão sobre o uso racional dos medicamentos (ALBUQUERQUE et al., 2018).

Acredita-se que conforme problemáticas abordadas no presente estudo alguns pontos são relevantes destacar, como a falta de compreensão dos usuários sobre o correto descarte dos medicamentos, quando foi verificado que em $81,3 \%$ os usuários são informados sobre a prática no momento da dispensação dos medicamentos, salientando uma preocupação dos profissionais. Ficando perceptível a falta de conhecimento, quando foi observada a quantidade de sobra de medicamentos $(85,8 \%)$ nas residências o que nos leva a outra grande adversidade que é a adesão ao tratamento somada ao grande descarte de medicamentos de uso contínuo. Ademais, o estudo aborda dados necessários para conscientização e organizações quanto aos municípios e rede de atenção à saúde, percebendo que o tratamento dos usuários inicia com a prevenção, caso necessário consulta e finalizando com o descarte dos medicamentos e correlatos prescritos para o tratamento visando diminuir custos para a sociedade e menor impacto ao meio ambiente. 


\section{CONCLUSÃo}

Este trabalho abordou a relevância da discussão sobre os RSS, os medicamentos descartados na FE e US do município de Lajeado somaram a um montante de 178.564 unidades, sendo percebido em relação a alguns anos atrás uma significativa diferença, evidenciando que a prática de descarte de resíduos com a implantação das coletoras em cada US está sendo fortalecida no município, porém ainda há muito o que ser desenvolvido. Os resultados trazem importantes contribuições para a região, deixando clara a necessidade de intervenção junto à gestão e responsáveis, para minimizar o problema do descarte inadequado

A legislação é o recurso para evitar que os resíduos sólidos de saúde sejam descartados em locais inapropriados tão relevante quanto é a fiscalização do cumprimento desta legislação e a conscientização da sociedade. A problemática da logística reversa e fracionamento dos medicamentos ainda deverá percorrer um longo caminho, mas pontos de coleta e campanhas de educação em saúde e ambiental podem ser uma alternativa promissora para que a temática seja divulgada e para que as pessoas se sensibilizem. 


\section{REFERÊNCIAS}

ABDI. Agência Brasileira de Desenvolvimento Industrial. Logística reversa, aplicada ao setor de medicamentos. Brasília, 2013.

ABNT - Associação Brasileira de Normas Técnicas. NBR 10004: Resíduos Sólidos: Classificação. Rio de Janeiro, 2004.

ABRELPE. Associação Brasileira de Empresas de Limpeza Pública e Resíduos Especiais. Panorama dos Resíduos Sólidos no Brasil. São Paulo: 2017.

ALBUQUERQUE, N.L.S.; OLIVEIRA, A.S.S.; SILVA, J.M.; ARAUJO, T.L. Association between follow-up in health services and antihypertensive medication adherence. Revista Brasileira de Enfermagem. Brasília, v.71, n. 6, nov./dez 2018.

AITKEN, M.; KLEINROCK, M.; SIMORELLIS, A.; NASS, D. The Global Use of Medicine in 2019 and Outlook to 2023. USA: IQVIA, 2019.

ANVISA. Agência Nacional de Vigilância Sanitária. Resolução de Diretoria Colegiada (RDC) ํㅡㄹ, de 5 de maio de 2011.

ANVISA. Agência Nacional de Vigilância Sanitária. Resolução de Diretoria Colegiada (RDC) n 80, de 11 de maio de 2006.

ATC. ANATOMICAL THERAPEUTICAL CHEMICAL CLASSIFICATION SYSTEM NORDIC COUNCIL ON MEDICINES; 2008. Disponível em: <http://www.whocc.no/atcddd/indexdatabase/>. Acesso em 2 nov. 2020.

AURÉLIO, Cecília Juliani. Estratégias para operacionalização da logística reversa de medicamentos. 2015. 112f. Dissertação (Mestrado em Sustentabilidade) - Escola de Artes, Ciência e Humanidades, Universidade de São Paulo, São Paulo, 2015. Disponível em:

<http://www.teses.usp.br/teses/disponiveis/100/100136/tde-07012016-

142615/en.php>. Acesso em 10 out. 2020. 
BELLAN, N.; PINTO, T. J. A.; KANEKO, T.M.; MORETTO, L. D.; JUNIOR, N. S. Critical analysis of the regulations regarding the disposal of medication waste. 54 INOVAE ISSN: 2357-7797, São Paulo, Vol.8, JAN-DEZ, 2020 - pág. 33-56 Brazilian Journal of Pharmaceutical Sciences. São Paulo, v. 48, n. 3, p. 507-513, jul/set. 2012.

BHS - Brasil Health Service. Programa Descarte Consciente. Disponível em: <http://www.bhsbrasil.com.br/descarteconsciente/>. Acesso 10 out. 2020.

BILA, D.M.; DEZOTTI, M. Identificação de fármacos e estrogênios residuais e suas consequências no meio ambiente. In: Programa de Engenharia Química/CoppeUFRJ, organizador. Fronteiras da engenharia química. v. 1. Rio de Janeiro: CoppeUFRJ; 2005. p. 141-175.

BJPS - Brazilian Journal of Pharmaceutical Sciences - Anais do XX Congresso Farmacêutico de São Paulo, 2019. Disponível em: <http://scielousp.webhostusp.sti.usp.br/wp-content/uploads/2020/03/AnaisXXCongressodeFarmaciaSP-BJPS-final2.pdf>. Acesso em 15 out. 2020.

BRASIL. Ministério da Saúde. Secretaria de Ciência, Tecnologia e Insumos Estratégicos. Departamento de Assistência Farmacêutica e Insumos Estratégicos. Brasília, 2012. Biblioteca Virtual em Saúde do Ministério da Saúde: <http://www.saude.gov.br/bvs>. Acesso em 15 out. 2020.

BRASIL, Ministério do Meio Ambiente. Lei ํำ № 9.605, de 12 de fevereiro de 1998, Lei dos Crimes Ambientais.

BRASIL, Lei № 12.305 de 2 de agosto de 2010, Política Nacional de Resíduos Sólidos (PNRS), Brasília: 2010.

BRASIL, Ministério do Meio Ambiente. Conselho Nacional do Meio Ambiente (CONAMA). Resolução no 358, de 29 de abril de 2005.

BRASIL, Ministério da Saúde. Agência Nacional de Vigilância Sanitária. Resolução da Diretoria Colegiada - RDC nº 222, de 28 de março de 2018 comentada. Disponível em:

<http://portal.anvisa.gov.br/documents/33852/271855/RDC+222+de+Mar\%C3\%A7o+ de+2018+COMENTADA/edd85795-17a2-4e1e-99ac-df6bad1e00ce?version=1.0>. Acesso em 5 out. 2020.

CARVALHO, E.V., FERREIRA E, MUCINI L, SANTOS C. Aspectos legais e Toxicológicos do descarte de medicamentos. Rev. Bras. Toxicol. 22(1): 1-8, 2009.

CASTRO, H.C. et al. Automedicação: entendemos o risco? Infarma, v.18, n. 9-10, 2006.

CELLE-JEANTON, H.; SCHEMBERG, D., MOHAMMED, N.; HUNEAU, F.; BERTRAND, G.; LAVASTRE, V.; LE COUSTUMER, P. Evaluation of pharmaceuticals 
in surface water: reliability of PECs compared to MECs. Environ Int 73:10-21, 2014.

CFF. Conselho Federal de Farmácia. Guia de Farmácia, 2017.

CFF. Conselho Federal de Farmácia. Uso de Medicamentos Instituto Datafolha, 2019.

CRESTANA, G.B.; SILVA, J.H. Fármacos residuais: panorama de um cenário negligenciado. Rev. Internac. Direito e Cidadania. 9: 55-65, 2011.

CYCLAMED. Documento eletrônico. Disponível em <https://www.cyclamed.org/>. Acesso em 14 out. 2020.

DEBLONDE T.; COSSU-LEGUILLE C.; HARTEMANN, P. Emerging pollutants in wastewater: A review of the literature. International Journal of Hygiene and Environmental Health. Jena, v. 214, p. 442-448, 2011.

FALQUETO, E.; KLIGERMAN, D.C.; ASSUMPÇÃO, R.F. Como realizar o correto descarte de resíduos de medicamentos? Ciência \& Saúde Coletiva, 15 (Supl. 2):32833293, 2010.

FEPAM - FUNDAÇÃO ESTADUAL DE PROTEÇÃO AMBIENTAL HENRIQUE LUIS ROESSLER. Disponível em: <http://www.fepam.rs.gov.br/> Acesso em: Outubro/2020.

FERNANDES M.R., ROCHA R.S., SILVA I.R., FIGUEIREDO R.C., BALDONI A.O. Prevalência e fatores associados à presença de medicamentos vencidos em estoques caseiros. Cad Saúde Colet, 2020;28(3):390-399. Disponível em: <https://doi.org/10.1590/1414- 462X202028030535>

GASPARINI, J.C.; GASPARINI, A.R.; FRIGIERI, M.C. Estudo do descarte de medicamentos consciência ambiental no município de Catanduva-SP. Rev. Ciência \& Tecnologia, v. 2, n. 1, p. 38-51, 2011.

IBGE - Instituto Brasileiro de Geografia e Estatística, Brasil, 2017. Disponível em: $<$ https://www.ibge.gov.br/> Acesso em outubro/2020.

IDF. International Diabetes Federation. IDF Atlas. 7th ed. Brussels, Belgium: International Diabetes Federation; 2015.

INTERFARMA - Associação da Indústria Farmacêutica de Pesquisa 2019. Disponível em: < https://www.interfarma.org.br/>. Acesso em outubro/2020

IPEA. Diagnóstico dos Resíduos Sólidos de Logística Reversa Obrigatória. Brasília, 2012.

JOÃO, Walter da Silva Jorge. Descarte de medicamentos. Pharmacia Brasileira. n. 87, 2013. 
KUMMERER, K. The presence of pharmaceuticals in the environment due to human use - present knowledge and future challenges. Journal of Environmental Management. New York, v. 90, p. 2354-2366, 2009b.

LOLIĆ A., PAÍGA P., SANTOS L.H.M.L.M, RAMOS S., CORREIA M., DELERUEMATOS, C. Assessment of non-steroidal anti-inflammatory and analgesic pharmaceuticals in seawaters of North of Portugal: occurrence and environmental risk. Sci Total Environ 508:240-250, 2015.

MARCHI, C. M. D. F. Cenário Mundial Dos Resíduos Sólidos e o Comportamento Corporativo Brasileiro Frente À Logística Reversa. Perspectivas em Gestão \& Conhecimento, João Pessoa, v. 1, n. 2, p. 118-135, jul./dez. 2011.

MARQUES, Ronualdo; XAVIER, Cláudia Regina. RESPONSABILIDADE SOCIOAMBIENTAL A PARTIR DA UTILIZAÇÃO E DESCARTE DE MEDICAMENTOS. Revbea, São Paulo, V. 13, № 4: 174-189, 2018.

MEDEIROS, M. S. G., MOREIRA, L. M. F., LOPES, C.C.G.O., Descarte de medicamentos: programas de recolhimento e novos desafios. Rev Ciênc Farm Básica Apl., 2014;35(4):651-662 ISSN 1808-4532.

MEEP, Mostra de Ensino, Extensão e Pesquisa (15: 2013: Lajeado, RS) Anais da XV Mostra de Ensino, Extensão e Pesquisa. - Lajeado: Ed. da Univates. 270-270, 2013

MELO S.A.S, TROVÓ A.G, BAUTITZ I.R, NOGUEIRA R.F.P. Degradação de fármacos residuais por processos oxidativos avançados. Quím. Nova. 32(1): 188-197, 2009.

MURAKAMI, I.; NETO, L.M.R.; SILVA, A.M. A importância do fracionamento de medicamentos para o SUS: um estudo piloto. Rev. Bras. Farm. 93(2): 221-224, 2012

OLIVEIRA, Neylson Dias de. Estudo da Implementação do fracionamento de medicamentos no Brasil: aspectos regulatórios, acesso e uso racional. Dissertação faculdade de Farmácia da Universidade Federal do Rio Grande do Sul, 2009.

PEÑA-GUZMÁN C., ULLOA-SÁNCHEZ S., MORA K., BUSTOS H. R., LOPEZBARRERA E., ALVAREZ J., RODRIGUEZ-PINZÓN M. Emerging pollutants in the urban water cycle in Latin America: a review of the current literature. J Environ Manag 237:408-423, 2019.

PERS-RS - Plano Estadual de Resíduos Sólidos do Rio Grande do Sul 2015 - 2034. Disponível em: <https://www.sema.rs.gov.br/plano-estadual-de-residuos-solidos> Acesso em: Outubro/2020

PINTO, G. M. F., SILVA, K. R.; PEREIRA, R. F. A. B.; SAMPAIO, S. I. Estudo do descarte residencial de medicamentos vencidos na região de Paulínia (SP), Brasil. Revista Engenharia Sanitária e Ambiental, Rio de Janeiro, v.19, n.3, p. 219-224, 2014. 
PIZZOLATO T.M., SANTOS J.H.Z.S., CUNHA A.C.B. Desenvolvimento de metodologia analítica para quantificação de fármacos em meio aquático por extração em fase sólida e High Performance Liquide Chromatography (HPLC). Rev. Ci. Amb. 1(2): 19-34, 2007.

PNUMA. Programa das Nações Unidas para o Meio Ambiente, 1975. Disponível em: https://www.unenvironment.org/pt-br/sobre-onu-meio-ambiente.

PNUMA. Programa das Nações Unidas para o Meio Ambiente, 2020. Disponível em: https://www.unenvironment.org/pt-br/noticias-e-reportagens/reportagem/embalagembiodegradavel-para-medicamentos-vence-concurso

RAMOS, Hayssa Moraes Pintel; CRUVINEL, Vanessa Resende; NOGUEIRA, Meiners; MICHELINE, Marie Milward De Azevedo; QUEIROZ, Camila Araújo; GALATO, Dayani. Ambiente \& Sociedade, São Paulo v. XX, n. 4 p. 149-174 out.-dez. 2017.

RIO GRANDE DO SUL, Lei oㅜ 13.905 de 10 de janeiro de 2012. Obrigatoriedade das farmácias e drogarias manterem recipientes para coleta de medicamentos, cosméticos, insumos farmacêuticos e correlatos, deteriorados ou com prazo de validade expirado. Disponível em: <https://www.normasbrasil.com.br/norma/lei13905-2012-rs_155871.html>

RODRIGUES, I.C.G; GARCIA, I.F; SANTOS, V.L.P.; RIBAS, J.L.C. Contaminação ambiental decorrente do descarte de medicamentos: participação da sociedade nesse processo. Braz. J. of Develop., Curitiba, v. 6, n. 11, p. 86701-86714, nov. 2020.

ROVERI, Vinicius; GUIMARÃES, Luciana Lopes; TOMA, Walber; CORREIA, Alberto Teodorico. Occurrence and ecological risk assessment of pharmaceuticals and cocaine in a beach area of Guarujá, São Paulo State, Brazil, under the influence of urban surface runoff. Springer-Verlag GmbH Germany, part of Springer Nature 2020.

SBC - Sociedade Brasileira de Cardiologia. $7^{\text {a }}$ Diretriz Brasileira de Hipertensão Arterial. Rio de Janeiro: MS, 2016.

SBD. Diretrizes da Sociedade Brasileira de Diabetes 2017-2018 / Organização José Egídio Paulo de Oliveira, Renan Magalhães Montenegro Junior, Sérgio Vencio. -- São Paulo: Editora Clannad, 2017.

SNIS - SISTEMA NACIONAL DE INFORMAÇÕES SOBRE SANEAMENTO: diagnóstico do manejo de resíduos sólidos urbanos - 2012. 11. Ed. Brasília: 2014.

SILVA, A. L. E., MORAES, J. A. R., REHBEIN, A., BENCKE, D., GERHARD, G. Posicionamento das farmácias e a logística reversa no controle dos medicamentos em desuso. Santa Cruz do Sul: Revista Eletrônica em Gestão, Educação e Tecnologia Ambiental - REGET, 2014.

TAMTAM, F.; OORT, F.; BOT, B. L.; DINH, T.; MOMPELAT, S.; CHEVREUIL, M.; 
LAMY, I.; THIRY, M. Assessing the fate of antibiotic contaminants in metal contaminated soils four years after cessation of long-term wastewater irrigation Science of the Total Environment. Amsterdam, v. 409, p. 540-547, 2011.

UEDA J, Tavernaro R, Marostega V, Pavan W. Impacto ambiental do descarte de fármacos e estudo da conscientização da população a respeito do problema. Rev. Ci. Amb. 5(1): 1-6, 2009.

UFRGS. Fármacos na água: quão potável é a água que sai das nossas torneiras? Disponivel em: https://www.ufrgs.br/farmacologica/2018/11/29/farmacos-na-agua/ Acesso em: Outubro/2020.

WHO. Collaborating Centre for Drug Statistics Methodology Guidelines for ATC classification and DDD assignment 2020. Oslo, Norway, 2020.

WILSON, D.C. Development drivers for waste management. Waste Management \& Research, v. 25, n. 3, p. 198-207, 2007.

WORRELL, W.; VESILIND, P. Solid waste engineering. 2. ed. Stamford: Cengage Learning. 432 p, 2011.

ZAPPAROLI I.D., CAMARA M.R.G., BECK, C. Medidas mitigadoras para a indústria de fármacos Comarca de Londrina - PR, Brasil: impacto ambiental do despejo de resíduos em corpos hídricos. In 3. International Workshop Advanced in Cleaner Production. Cleaner Production Initiatives and Challenges for a Sustainable World. São Paulo, 2011. 